OPEN ACCESS

Edited by:

William Ying Khee Hwang, National Cancer Centre Singapore, Singapore

Reviewed by:

Stanislaw Stepkowski, University of Toledo, United States Barbara L. Kee, University of Chicago, United States

${ }^{*}$ Correspondence: Xiang-Yu Zhao zhao_xy@bjmu.edu.cn

Specialty section:

This article was submitted to Alloimmunity and Transplantation, a section of the journal

Frontiers in Immunology

Received: 27 September 2020 Accepted: 01 March 2021 Published: 18 March 2021

Citation:

Wang $X$ and Zhao X-Y (2021) Transcription Factors Associated With IL-15 Cytokine Signaling During NK Cell Development.

Front. Immunol. 12:610789. doi: 10.3389/fimmu.2021.610789

\section{Transcription Factors Associated With IL-15 Cytokine Signaling During NK Cell Development}

\author{
Xiang Wang ${ }^{1}$ and Xiang-Yu Zhao ${ }^{1,2 *}$ \\ 1 Peking University People's Hospital, Peking University Institute of Hematology, Beijing Key Laboratory of Hematopoietic \\ Stem Cell Transplantation, National Clinical Research Center for Hematologic Disease, Beijing, China, ${ }^{2}$ Beijing Engineering \\ Laboratory for Cellular Therapy, Beijing, China
}

Natural killer (NK) cells are lymphocytes primarily involved in innate immunity and possess important functional properties in anti-viral and anti-tumor responses; thus, these cells have broad potential for clinical utilization. NK cells originate from hematopoietic stem cells (HSCs) through the following two independent and continuous processes: early commitment from HSCs to IL-15-responsive NK cell progenitors (NKPs) and subsequent differentiation into mature NK cells in response to IL-15. IL-15 is the most important cytokine for NK cell development, is produced by both hematopoietic and nonhematopoietic cells, and functions through a distinct delivery process termed transpresentation. Upon being transpresented to NK cells, IL-15 contributes to NK cell development via the activation of several downstream signaling pathways, including the Ras-MEK-MAPK, JAK-STAT5, and PI3K-ATK-mTOR pathways. Nonetheless, the exact role of IL-15 in NK cell development has not been discussed in a consecutive and comprehensive manner. Here, we review current knowledge about the indispensable role of IL-15 in NK cell development and address which cells produce IL-15 to support NK cell development and when IL-15 exerts its function during multiple developmental stages. Specifically, we highlight how IL-15 supports NK cell development by elucidating the distinct transpresentation of IL-15 to NK cells and revealing the downstream target of IL-15 signaling during NK cell development.

Keywords: IL-15, signaling/signaling pathways, natural killer cell, development, transcription factor

\section{INTRODUCTION}

NK cells constitute the third most abundant lineage of lymphocytes in the peripheral blood after B and T cells, accounting for approximately $8-15 \%$ of circulating cells in humans or $2-6 \%$ in mice (1). Similar to $\mathrm{CD}^{+}$cytotoxic T lymphocytes, NK cells effectively eliminate virus-infected cells and malignant cells by producing proinflammatory cytokines and directly lysing target cells. NK cell activation is determined by the balance between signals transduced from multiple activating receptors and inhibitory receptors, which interact with their cognate ligand on target cells $(2,3)$.

Interleukin (IL)-15, a member of the common gamma chain cytokine family, was first described as a T cell growth factor, like IL-2 (4). IL-15 signals through a heterotrimeric receptor consisting of IL-15R $\alpha$ (CD215), IL-2/IL-15R $\beta$ (CD122) and the common $\gamma$ chain ( $\gamma$, CD132) (5). Similar to IL-2, IL-15 requires the receptors IL-2/IL-15R $\beta$ and $\gamma$ to transduce signaling but differs from IL-2 by 
virtue of its private binding receptor IL-15R $\alpha$, which is incapable of transducing signaling but has high affinity for IL-15 and forms a complex (IL-15-IL-15R $\alpha$ ) in IL-15-expressing cells $(4,6,7)$. These IL-15/IL-15R $\alpha$ complexes have the potential to stimulate neighboring cells that express IL-2/IL-15R $\beta$ and $\gamma$ via a unique mechanism referred to as tanspresentation $(8,9)$. Since the discovery of transpresentation, increasing evidence has suggested that IL-15 responses are largely mediated by transpresentation at steady state $(10,11)$.

NK cells primarily develop in the bone marrow (BM), which contains abundant hematopoietic stem cells (HSCs) capable of differentiating toward NK cells through common lymphoid progenitor (CLP) and lineage-restricted progenitor (NKP) cells (12). Multiple internal pathways and external factors contribute to the development of NK cells from HSCs (13). Most importantly, the pleiotropic cytokine IL-15 is indispensable for the development and homeostasis of NK cells as highlighted by their significant deficiency in IL-15-deficient mice. Correspondingly, deficiency in IL-15 or any one of the IL-15 receptor subunits, such as the IL$15 \mathrm{R} \alpha, \mathrm{IL}-15 \mathrm{R} \beta$, and $\gamma$ in mice, results in a dramatic paucity of mature NK cells (14-17). Parallel with the role of IL-15 in mice, several studies have demonstrated that the early commitment of NK cells from human CD $34^{+}$hemopoietic progenitor cells into NKP cells is dependent on the coordinated function of IL-3, IL-7, ckit ligand (KL), and flt3 ligand (FL) but not IL-15, whereas IL-15 is involved in the emergence of $\mathrm{CD}^{+} 6^{+} \mathrm{NK}$ cells $(18,19)$. Furthermore, Huntington et al. demonstrated that human NK cell differentiation that occurs in a linear fashion from $\mathrm{CD} 56{ }^{\mathrm{hi}} \mathrm{CD} 16^{-} \mathrm{KIR}^{-}$to $\mathrm{CD} 56{ }^{\mathrm{lo}} \mathrm{CD} 16^{+} \mathrm{KIR}^{-}$and finally to $\mathrm{CD} 56^{\mathrm{lo}} \mathrm{CD} 16^{+} \mathrm{KIR}^{+}$requires IL-15 in a humanized model (20). Collectively, these findings illustrate that IL-15 signaling is essential for NK cell development and homeostasis in both mice and humans. Interestingly, Sun et al. recently reported that the requirement of IL-15 for NK cell development could be partially overcome by acute mouse cytomegalovirus (MCMV) infection, as IL-12 but not IL-15 primarily drives the anti-viral response of NK cells even in mice lacking the $\chi(21)$. Further studies are required to investigate whether this represents an IL-15-independent NK cell development manner.

Due to the critical role of IL-15 in NK cell development, dissecting the signaling pathways that allow IL-15 to control the development and homeostasis of NK cells is fundamental to determine the molecular details of immune regulation. In this review, we provide an overview of the specific IL-15 signaling that transcriptionally regulates NK cell development and maturation.

\section{WHEN DOES IL-15 PROMOTE NK CELL DEVELOPMENT?}

\section{IL-15 Is Dispensable for NK Cell Commitment but Promotes Later Development}

Mice and human NK cells are generated from HSCs through multiple but sophisticated stages in specific developmental niches with internal and external regulatory pathways governing NK cell development. In brief, NK cell development primarily involves the following two independent and continuous processes: early NK cell commitment to IL-15responsive NKPs and subsequent phenotypical and functional maturation of NK cells in response to IL-15. Early NK cell commitment to NKP cells is characterized by the acquisition of CD122 (IL-15R $\beta$ ), which is a critical subunit of the IL-15 receptor and dimerizes with $\gamma$ to transduce IL-15 signaling $(22,23)$. However, IL-15 is not involved in the generation of IL15-responsive NKPs because the IL-15 receptor is not expressed prior to the NKP stage (24). Recently, pre-NKP cells were identified as the earliest committed NK cell progenitors in murine BM, and these cells reside downstream of CLP and differentiate into NKPs (23). Although pre-NKP cells express undetectable levels of CD122, they are fully committed to the NK lineage both in vitro and in vivo. Therefore, IL-15 is not necessary for NK cell lineage commitment. Furthermore, mice deficient in $\gamma c$ exhibit an intact NKP compartment (16), and IL-3, IL-7, KL, and FL synergistically drive the differentiation of NKP cells from human HSCs in vitro in the absence of IL-15 (25). Conversely, IL-15 is indispensable for the later development of NK cells. The expression of CD122 endows NK cells with the capacity to be responsive to IL-15; thus, these cells can become phenotypically and functionally mature and exhibit survival in response to IL-15 (16).

\section{IL-15 Receptor Expression Varies in Different Stages of NK Cell Development}

Intriguingly, the expression of CD122 on NK cells is not static but dynamically changes with NK cell maturation. It has been previously demonstrated that CD $56^{\text {bright }} \mathrm{NK}$ cells express higher levels of CD122 as well as elevated CD122 transcripts compared with $\mathrm{CD} 56^{\mathrm{dim}} \mathrm{NK}$ cells, and thus are intrinsically more responsive to IL-15 (26-29). This observation explains the decreased proliferation capacity in response to IL-15 or dendritic cell (DC) stimulation during NK cell maturation (30, 31) and is consistent with the fact that cytokines, such as IL-2 and IL-15, fail to reverse the proliferation defects of CD57 $7^{+}$ terminally matured NK cells (32). Consistent with the observation in human NK cells, CD122 expression is significantly decreased during maturation from mice $\mathrm{CD} 11 \mathrm{~b}^{+} \mathrm{CD} 27^{+} \mathrm{NK}$ cells to $\mathrm{CD} 11 \mathrm{~b}^{+} \mathrm{CD} 27^{-} \mathrm{NK}$ cells and concomitant with decreased proliferation capacity (33). Despite the vitally important role of IL-15 in NK cell maturation, the exact role of decreased CD122 expression during NK cell terminal maturation needs to be further elucidated.

\section{Transcriptional Regulation of IL-15 Receptor Expression at Different Stages During NK Cell Development}

Although CD122 (encoded by Il2rb) is critical for NK cell development by transducing IL-15 signaling, the coordinated regulation of CD122 expression by various transcription factors remains elusive. Previous studies have demonstrated that RUNX3 (one of the Runx family transcription factors), T-bet, and Eomesodermin (Eomes) directly bind to the promoter 
region of Il2rb and induce CD122 expression $(34,35)$. However, these transcription factors are not simultaneously functional, but rather function at different stages of NK cell development. In the NK cell development pathway, RUNX3 expression is initiated at the NKP stage. The inactivation of RUNX3 in HSCs partially disturbed the generation of $\mathrm{CD} 122^{+} \mathrm{NKP}$ cells in vitro but not completely, indicating that other unknown transcription factors contribute to the expression of CD122 during NK cell commitment. In addition, the deletion of RUNX3 in immature NK cells in mice only slightly reduced CD122 expression on NK cells, and the absolute number of NK cells was not significantly affected. These results confirmed that RUNX3 is necessary for the acquisition of CD122 during NK cell lineage commitment but is not essential for the maintenance of CD122 at the later maturation stages of NK cell development (34).

In contrast, T-bet and Eomes are weakly expressed at the NKp stage but highly expressed during NK cell maturation; therefore we speculated that T-bet and Eomes are not firmly involved in the induction of CD122 at the NKp stage but may contribute to the maintenance of CD122 expression during maturation (35, 36). Consistently, mice harboring genomic deletions of T-bet and Eomes lack NK cells, but CD122 ${ }^{\text {hi }}$ precursors of NK cells were observed (36). In addition, the deletion of Eomes in mice results in significantly decreased CD122 expression at different stages of NK cell maturation $(33,35,37)$. Moreover, Eomes ${ }^{+}$NK cells express more CD122 and proliferate better than Eomes ${ }^{-} \mathrm{NK}$ cells, which are called Innate Lymphoid Cells (ILCs) 1 now (38, 39). However, CD122 expression is upregulated in T-betdeficient NK cells, and this finding may be attributed to increased Eomes expression, which is repressed by T-bet (40). These results indicate that Eomes but not T-bet plays a dominant role in the maintenance of CD122 expression during NK cell maturation. Consistently, although T-bet expression is upregulated during the $\mathrm{NK}$ cell transition from the $\mathrm{CD}_{11 b^{+} \mathrm{CD} 27^{+}}$to $\mathrm{CD} 11 \mathrm{~b}^{+} \mathrm{CD} 27^{-}$stage, $\mathrm{CD} 122$ expression is progressively decreased, accompanied by a reduction in Eomes expression (33).

In conclusion, the induction of CD122 during early NK cell commitment is dependent on RUNX3, whereas Eomes but not T-bet maintains the expression of CD122 to promote NK cell maturation (Figure 1).

\section{WHICH CELLS PRODUCE IL-15 TO PROMOTE NK CELL DEVELOPMENT?}

\section{Isolated Expression of IL-15 mRNA and Protein}

IL-15 mRNA is constitutively expressed in a broad range of tissues, including hematopoietic cells [monocytes, macrophages, and dendritic cells (DCs)] and non-hematopoietic cells (epithelial cells, fibroblasts, nerve cells, skeletal muscle and keratinocytes) (4). In contrast to the widespread expression of IL-15 mRNA, IL-15 protein is only detectable in a more restricted population at steady state. This discrepancy between widespread IL-15 transcript expression and restricted protein expression is attributed to extensive checkpoints at transcription, translation, and intracellular trafficking, particularly posttranscriptional checkpoints. Multiple 5'-untranslated region (UTR) AUG sequences, a long signal peptide (LSP) (48 amino acid) and a negative regulatory element in the C-terminus of the
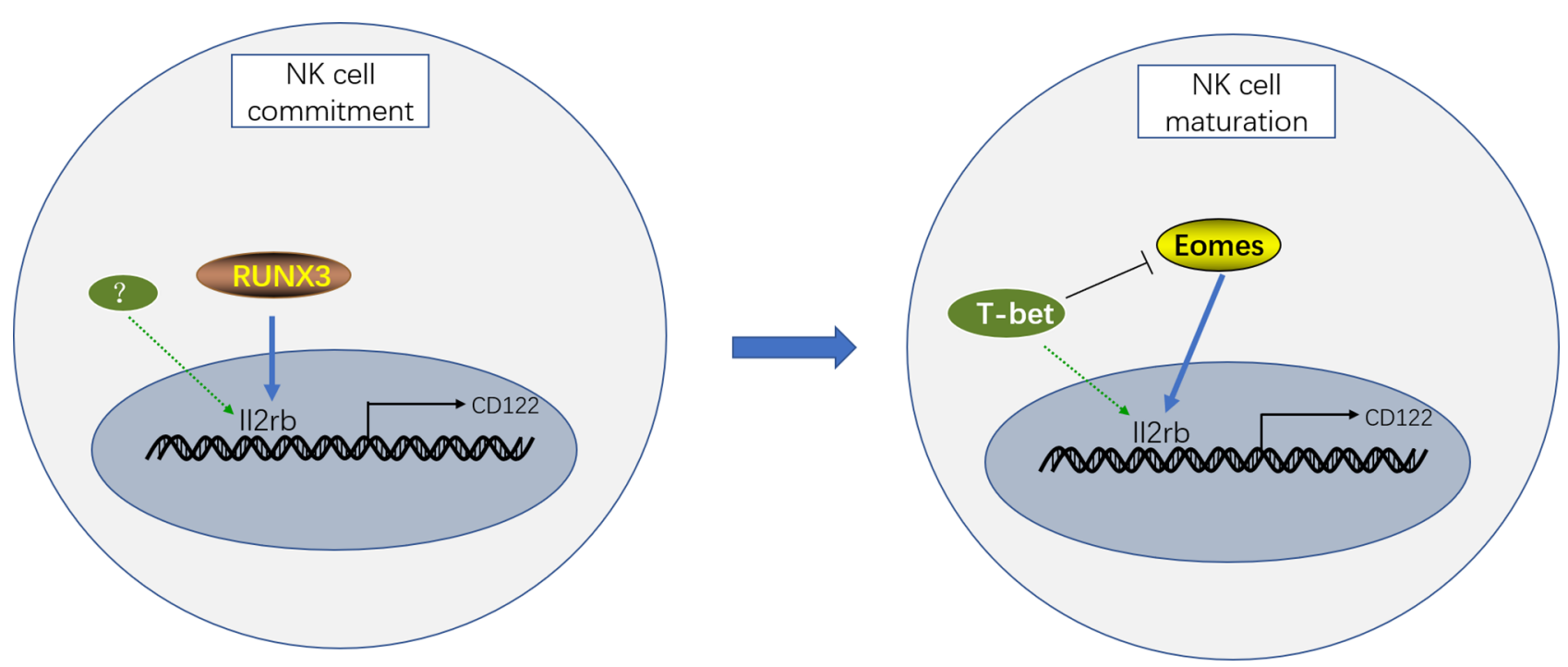

FIGURE 1 | Transcriptional regulation of CD122 expression during different stages of NK cell development. RUNX3 coordinates with T-bet and Eomes to control CD122 expression during NK cell development. Therein, the induction of CD122 expression during early NK cell commitment is determined by RUNX3 and other unknown transcription factors. Moreover, both T-bet and Eomes contribute to CD122 expression during NK cell maturation. However, Eomes but not T-bet plays a predominant role in the maintenance of CD122 expression to promote NK cell maturation. 
coding sequence and mature protein all contribute to impede translation (41-44). Surprisingly, a 250-fold increase in IL-15 expression is observed after the removal of those three predominant restraints, further demonstrating the contribution of multiple post-transcriptional mechanisms in limiting IL-15 translation (42). Additionally, there are two isoforms of IL-15 mRNA, differing in their signal peptide, which result in distinct intracellular trafficking, localization, and secretion patterns (4446). Both isoforms produce mature IL-15 protein. IL-15 with LSP is primarily located in the Golgi apparatus, early endosomes, and endoplasmic reticulum and functions as a secretory signal peptide, whereas IL-15 with a short signal peptide (SSP) (21 amino acid) is not secreted, appears to reside in the nucleus and cytoplasmic components (44). Tight regulation of IL-15 expression is important because of the potent capacity of IL-15 to promote inflammation.

\section{The Production of IL-15 by Hematopoietic and Non-Hematopoietic Cells}

Due to the extremely low level of IL-15 protein expression at steady state, even after stimulation, IL-15 is barely detectable by antibodies. However, the establishment of an IL-15 reporter mouse line allows IL-15-producing cells to be visualized by flow cytometry or fluorescence microscopy as well as immunohistochemistry in vivo (47-49). Among hematopoietic cells, IL-15 is predominantly produced by monocytes, macrophages, DCs, myeloid cells, and some early hematopoietic cells (Table 1) $(4,47)$. Therein, $\mathrm{CD}^{+}$conventional DCs are the major DC subsets responsible for IL-15 expression rather than plasmacytoid DCs $(47,48)$. Moreover, myeloid cells, including neutrophils, basophils, and eosinophils, express high levels of IL15 in vivo, whereas lymphoid lineages, such as T cells, B cells, NKT cells, and NK cells, express minimal to undetectable IL-15 levels. Interestingly, LSK cells (Lineage ${ }^{-} \mathrm{Sca}-1^{+} \mathrm{c}-\mathrm{kit}^{+}$), which constitute a heterogeneous population of both long-term and short-term HSCs in BM, uniformly express high levels of IL-15.

Among nonhematopoietic cells, a distinct category of stromal cells together with epithelial cells directs IL-15 expression in primary and secondary lymphoid organs (Table 1) (49). In BM, IL-15 is predominantly expressed by VCAM $1^{+} \mathrm{PDGFR} \beta^{+} \mathrm{CD} 31^{-} \mathrm{Sca}-1^{-}$mesenchymal stromal cells, which correspond to a distinct subset of CXC chemokine ligand-12 (CXCL12)-abundant reticular (CAR) cells and may function as a developmental niche for NK cells $(50,51)$. In the thymus, IL-15 is highly expressed in the thymic medulla and medullary thymic epithelial cells with high MHC class II expression, providing a major source of IL-15. In the lymph nodes, IL-15-expressing cells, which include some fibroblastic reticular cells (FRCs) and gp $38^{-} \mathrm{CD}^{-} 1^{-}$stromal cells, primarily reside in the T-cell zone and medulla. In addition, in the lymph nodes, blood endothelial cells (BECs) also express high IL-15 levels. In the spleen, $\mathrm{VCAM}-1^{+}$stromal cells are responsible for IL-15 expression.

In contrast to the low expression of IL-15 at steady state, its expression capacity is further strengthened by several inflammatory stimuli, including Toll-like receptor (TLR) ligands and cytokines $(47,52-54)$. Previously, studies have proven that bacterial lipopolysaccharide (LPS) or the double-stranded RNA mimic Poly I:C initiates TLR signaling to induce IL-15 expression (55). Similarly, IL-15 induction is interferon (IFN)- $\alpha$ receptor (IFNAR)-dependent after viral infection (47). Although IL-15 mRNA is elevated in all DC subsets after inflammatory stimuli, only CD $8 \alpha+$ DCs upregulated IL-15 protein expression, further specifying a DC subset for IL-15 production $(47,55,56)$. Moreover, it has been demonstrated that upregulated IL-15 expression also exists in monocytes, macrophages, and tumorassociated neutrophils in inflammatory environments (57-59). In addition, LPS-induced inflammation also greatly increases IL-15 expression in stromal cells, including BECs and lymphatic endothelial cells (LECs), whereas this effect is not significant in other stromal cells (49).

\section{Both Hematopoietic and Non- Hematopoietic Cells Promote NK Cell Development by Producing IL-15}

The diverse subsets of IL-15-expressing cells play different but overlapping roles in the development of NK cells in BM and peripherally by producing and transpresenting IL-15 (Figure 2). Overall, hematopoietic cells were found to override the importance of non-hematopoietic cells in promoting NK cell development $(10,11)$. Correspondingly, restricting IL-15R $\alpha$ or IL-15 expression to hematopoietic cells completely recovered NK cell development at all stages in BM with a slight defect in peripheral mature NK cells, whereas the development of NK cells was only partially rescued in all tissues when IL-15R $\alpha$ or IL-15 expression was specifically limited to non-hematopoietic cells.

As a critical component of hematopoietic cells, monocytes, DCs, and macrophages contribute to NK cell development by producing IL-15. The indispensable role of monocytes in NK cell development and homeostasis was exemplified by the observation that the interaction between NK cells and spleen monocytes promotes $\mathrm{CD} 11 \mathrm{~b}^{+} \mathrm{CD} 27^{+} \mathrm{NK}$ cell differentiation into

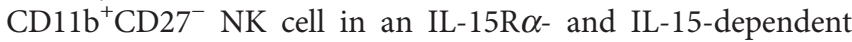
and cell-cell contact-dependent manner (60). Consistently,

TABLE 1 | The production of IL-15 by hematopoietic cells and non-hematopoietic cells. 


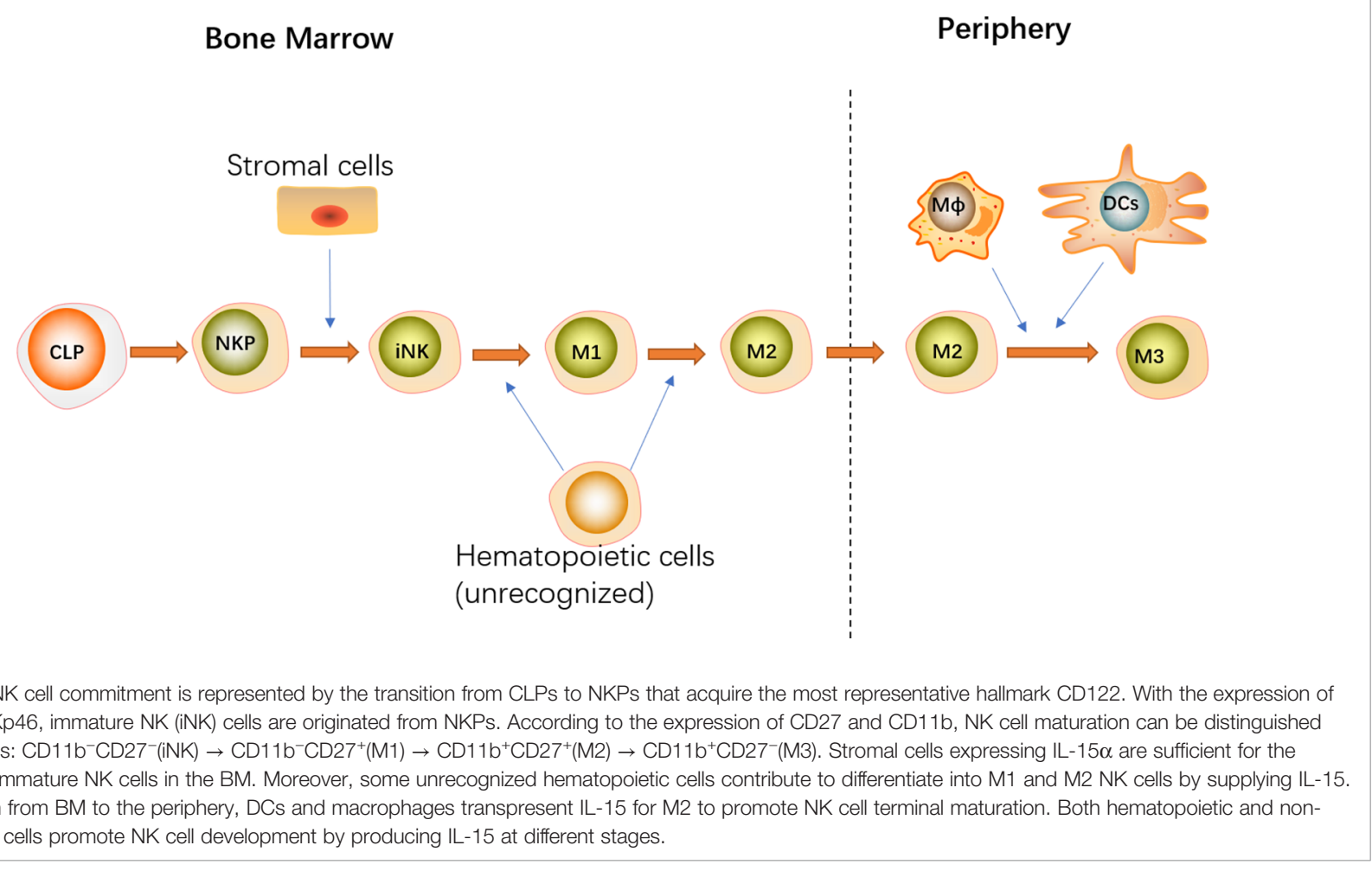

immunobiological studies revealed that monocytes and NK cells reside in close proximity of the red pulp of the spleen (60). Additionally, although IL-15R $\alpha$ expression on DCs and macrophages is dispensable for NK cell differentiation in BM, it is required for the maintenance of mature $\mathrm{NK}$ cells in the periphery given that specific knockdown of IL-15R $\alpha$ on DCs or macrophages results in a substantial reduction in NK cells in the periphery (61). Moreover, NK cell homeostasis is not exacerbated when IL-15R $\alpha$ is conditionally deleted from both DCs and macrophages, indicating that DCs and macrophages maintain NK cell populations in the peripheral blood and organs in a similar manner (61). Furthermore, mice with conditional deletion of IL-15R $\alpha$ in DCs or macrophages exhibit significant deficits in terminally differentiated $\mathrm{CD} 27^{-} \mathrm{CD} 11 \mathrm{~b}^{+} \mathrm{NK}$ cells, although the subsets of peripheral $\mathrm{CD} 27^{+} \mathrm{CD} 11 \mathrm{~b}^{-}$and $\mathrm{CD} 27^{+} \mathrm{CD} 11 \mathrm{~b}^{+} \mathrm{NK}$ cells remain intact. Thus, DCs and macrophages were dispensable for NK cell development in the $\mathrm{BM}$ and necessary for NK cells' terminal differentiation in the periphery. However, using CD11c/IL-15R $\alpha$ Tg mice with an IL$15 \mathrm{R} \alpha^{-/-}$background, Castillo et al. revealed that DCs contribute to the development of NK cells in both the BM and peripheral blood and organs. Mice that exclusively expressed IL-15R $\alpha$ on DCs exhibited partial recovery of NK cells in all tissues, and the greatest reconstitution was noted in the BM (10). Furthermore, IL-15 exclusive transpresentation via DCs is insufficient for the maturation of $\mathrm{CD} 27^{-} \mathrm{CD} 11 \mathrm{~b}^{+} \mathrm{NK}$ cells, which preferentially reside in the peripheral blood and organs. These discrepancies in the function of DCs during NK cell development may be attributed to divergent models. Nonetheless, transpresentation of
IL-15 by DCs and macrophages is not responsible for the all IL15 events attributed to IL-15R $\alpha+$ hematopoietic cells, as NK cell deficiency in the BM of mice with IL-15R $\alpha$ deletion in DCs or macrophages is less apparent than that observed in IL-15R $\alpha$ deficient mice $(10,61)$. Therefore, besides DCs and macrophages, other unrecognized hematopoietic cells in the $\mathrm{BM}$ that contribute to NK cell development have not been identified.

Moreover, IL-15 expression by non-hematopoietic cells is more important for NK cell development in BM other than in the periphery, as limiting IL-15R $\alpha$ expression to non-hematopoietic cells results in more evident NK cell recovery in BM, and this effect is virtually non-existent in the spleen or liver (10). Nonhematopoietic cells expressing IL- $15 \alpha$ are sufficient for the generation of immature NK cells but are incapable of NK cell maturation (10). This finding may be attributed to the high expression of IL-15 in CXCL12-abundant reticular (CAR) cells, which are in close contact with NK cells in BM (49-51). In addition to transducing the downstream signaling of $\mathrm{CXC}$ chemokine receptor (CXCR4), the engagement of CXCL-12 on CAR cells via CXCR4 expressed by NK cells also contributes to $\mathrm{NK}$ cell retention in BM, which provides a special IL-15sufficient niche for $\mathrm{NK}$ cell development. In vivo and in vitro studies demonstrated that the CXCL-12/CXCR4 axis is essential for NK cell maturation and proliferation $(50,51)$. However, the exact role of IL-15 expression in CAR cells is unidentified. Additionally, consistent with the high expression of IL-15 in fibroblastic reticular cells (FRCs) of lymphoid nodes, the specific ablation of IL-15 in FRCs results in almost complete abrogation 
of NK cells in Peyer's patches (PPs) and gut-associated secondary lymphoid organs (SLOs), indicating that FRCs promote NK cell homeostasis via the establishment of an IL-15-dependent niche (62).

Furthermore, human spleen-derived fibroblasts are sufficient for the development of functional $\mathrm{CD} 56^{\text {bright }} \mathrm{CD}^{-} \mathrm{NK}$ cells in vitro, and neutralizing IL-15 signaling or disturbing direct contact significantly abrogates $\mathrm{CD} 56^{\mathrm{dim}} \mathrm{CD}^{-} \mathrm{NK}$ cell generation, indicating that fibroblasts express and transpresent IL-15 to support NK cell development (63). However, no in vivo studies have demonstrated the role of fibroblasts in NK cell development. In conclusion, although previous studies have uncovered the distinct function of DCs and macrophages in NK cell development, the exact biological role of IL-15 expression in other hematopoietic cells (myeloid cells and early HSCs) and diverse stromal cells that reside in the BM or peripheral blood and organs during NK cell development remains poorly described.

\section{HOW DOES IL-15 TRANSPRESENTATION SUPPORT NK CELL DEVELOPMENT?}

Although IL-15 is critical for NK cell development, IL-15 alone only weakly activates its downstream signaling. In fact, the exertion of IL-15 function is dependent on IL-15R $\alpha$, which has high affinity to IL-15 (64). With the aid of IL-15R $\alpha$, IL-15 is protected from degradation, accumulates on the membrane and in the circulation of mice, and exhibits increased biological activity (65). Accordingly, IL-15-expressing cells must simultaneously express IL-15R $\alpha$ to supply IL-15 to IL-15responsive NK cells bearing $\mathrm{IL}-15 \mathrm{R} \beta$ and $\gamma_{c}(66,67)$. The distinct requirement is further unveiled by the discovery that IL-15 is preassembled with IL- $15 \mathrm{R} \alpha$ in a complex in the endoplasmic reticulum/Golgi and subsequently shuttled to the cell surface $(8,68)$. This cell surface complex is called membraneassociated IL-15-IL-15R $\alpha$ complex (mIL-15 complex) (Figure 3).

Nonetheless, the mIL-15 complex could be cleaved from the surface to form soluble IL-15-IL-15R $\alpha$ complex (sIL-15 complex) in response to several immune stimuli, including type I interferons (type I IFNs), Poly I:C stimulation, total body irradiation (TBI), Toll-like receptor (TLR) stimulation, virus infections, and activation of the stimulator of IFN genes (STING) pathway $(57,69,70)$. It is reported that this process is mediated by A Disintegrin and Metalloprotease (ADAM) 17 protease, whose expression is upregulated on the surface of IL-15 expressing cells after immune stimulus (69). Consistently, in vivo evidence demonstrated that the IL-15-IL-15R $\alpha$ complex exists in two forms, mIL-15 complex and sIL-15 complex, in humans and mice $(65,70)$. Although the sIL-15 complex was identified several years ago, its biological significance remains controversial. Interestingly, in vivo studies revealed that the sIL-15 complex serves as a potent agonist and is approximately 50-100 times more potent at promoting NK cell proliferation than recombinant IL-15 alone $(71,72)$. Thus, the sIL-15 complex may play an important role in stimulating IL-15 responses. Consistently, Anton et al. (73) demonstrated that low doses of

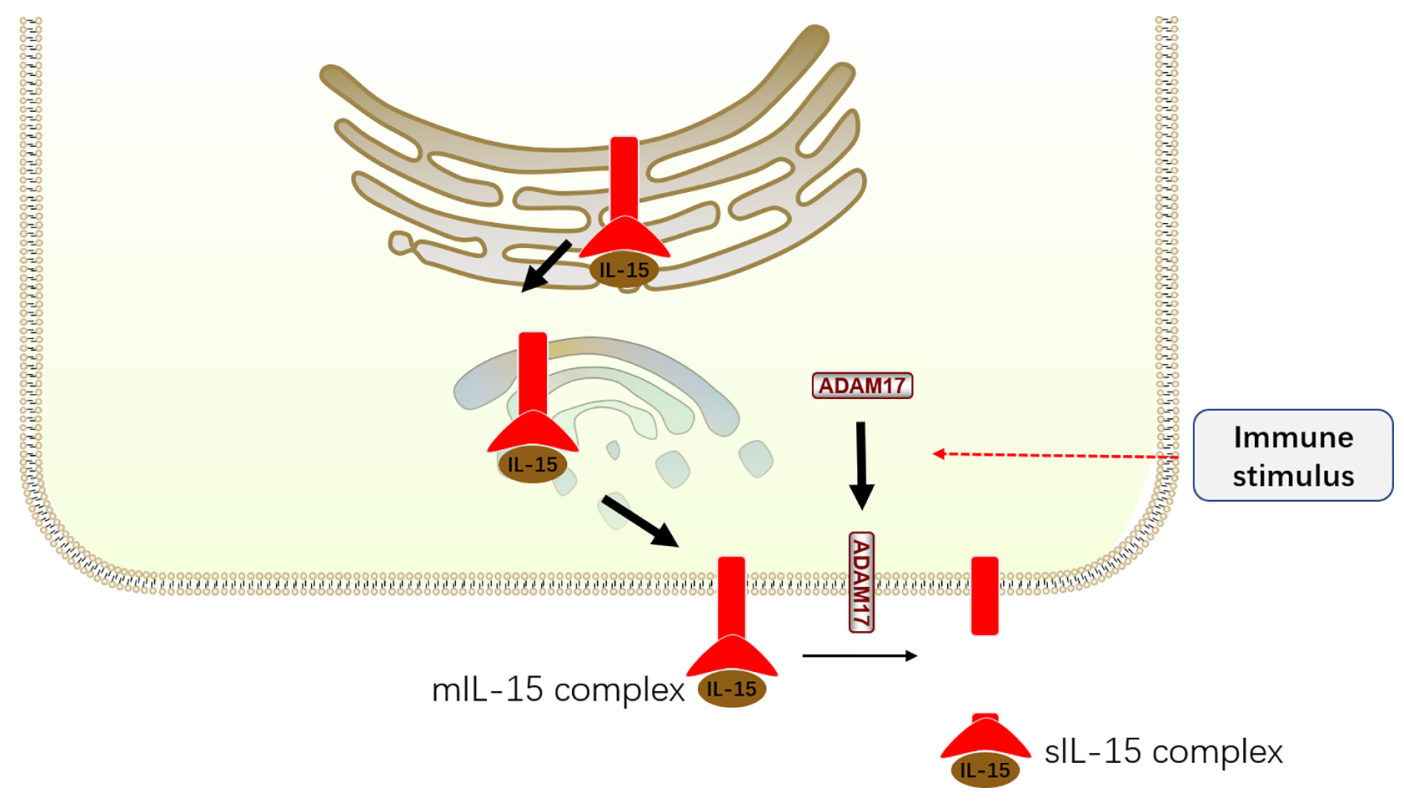

FIGURE 3 | The production of mIL-15 complex and sIL-15 complex. IL-15 preassembles with IL-15R $\alpha$ in a complex in the endoplasmic reticulum/Golgi and subsequently shuttled to the cell surface, becoming membrane-associated IL-15-IL-15R $\alpha$ complex (mIL-15 complex). After immune stimulating, the ADAM17 translocates to the cell surface with increased activity. The mIL-15 is cleaved by ADAM17 at the ectodomain of IL-15R $\alpha$ to induce the formation of soluble IL-15-IL$15 \mathrm{R} \alpha$ complex (sIL-15 complex). 
sIL-15 contribute to the phosphorylation of Stat5 in NK cells, whereas higher concentrations of sIL-15 are required to stimulate S6 phosphorylation in vitro. However, other studies discovered that the mIL-15 complex mediates NK cell activation rather than the sIL-15 complex present in the supernatants of IL15-expressing cells cultured in vitro or in the serum of mice ex vivo $(68,74)$. This contradiction may be attributed to the different experimental methods and low concentration of sIL15 complex in the supernatants and serum. Considering the rare detection of sIL-15 complex at steady states and substantial sIL15 complex produced after immune stimulation, we hypothesize that the sIL-15 complex mediates IL-15 responses during immune activation but not during steady states. However, due to the technological limitation, it is hard to distinguish IL-15 responses mediated by sIL-15 complex from mIL-15 complex.

In contrast to the sIL-15 complex, which functions independently of cell-cell interactions, the mIL-15 complex functions through a distinct delivery mechanism termed transpresentation during cell-cell contact to transduce IL-15 signaling to NK cells via the IL-12/IL-15R $\beta$ and $\gamma c$ complex (8, 64). Consistently, although IL- $15 \mathrm{R} \alpha$ knockout mice exhibit dramatic defects in NK cell development (15), the specific deletion of IL-15R $\alpha$ in NK cells has no detrimental effect on NK cell development. However, adoptive transfer of normal NK cells into IL-15R $\alpha$-deficient mice results in the abrupt loss of these cells, indicating that IL-15R $\alpha$ expressed by non-NK cells but not NK cells is required to mediate IL-15 signaling for NK cell development $(75,76)$.

During transpresentation, the IL-15R $\alpha$-IL-15 complex functions through three different mechanisms to transduce IL15 signaling in NK cells $(73,77)$ (Figure 4). First, presenting cells can directly interact with NK cells via the formation of an immunologic synapse where the membrane-associated IL$15 \mathrm{R} \alpha$-IL-15 complex on presenting cells interacts with the IL$15 \mathrm{R} \beta-\gamma \mathrm{c}$ receptor at the plasma membrane of $\mathrm{NK}$ cells to transduce IL-15 signaling. Consistently, the mIL-15 complex expressed by DCs accumulates at the synapse with NK cells, and the use of an antibody to block IL-15R $\alpha$ promotes NK cell apoptosis and significantly reduces NK cell survival (78). In addition to the IL-15/IL-15R $\alpha$ - $\beta / \gamma$ c interaction, many other receptor-ligand interactions may simultaneously occur at NK cell immunologic synapses, such as interactions between activating receptors or inhibitory receptors and their ligands, separately $(78,79)$. Interestingly, using a confocal microscopy assay, the mIL-15 complex accumulated in the periphery of activating synapses, whereas the mIL-15 complex was evenly distributed along the entire contact area when the NK cell line made contact with IL-15-expressing cells (79). Nonetheless, the

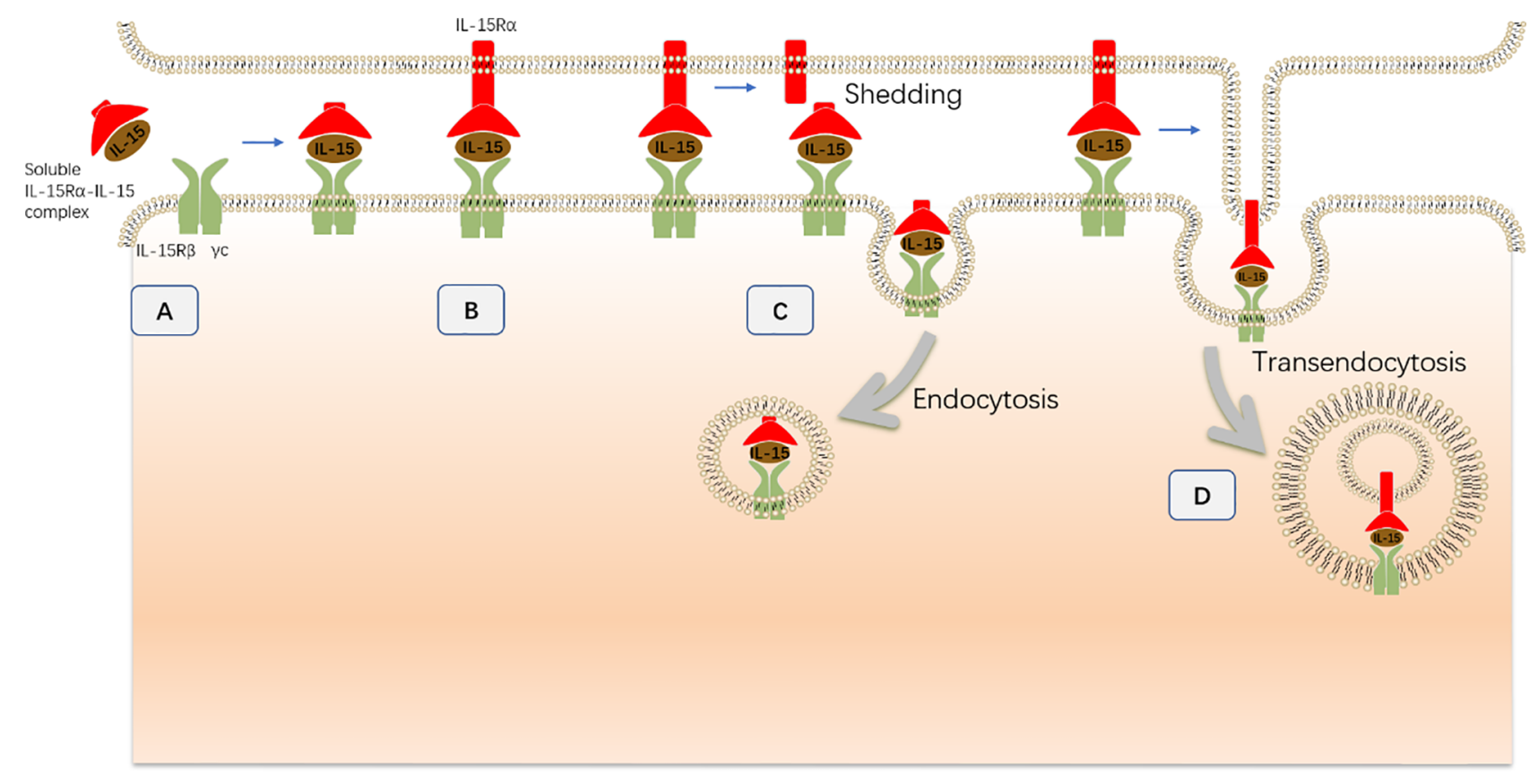

FIGURE 4 | The transpresentation of IL-15 to NK cells during NK cell development. (A) The sIL-15 complex (soluble IL-15-IL-15R $\alpha$ complex), which exists as a soluble extracellular complex in serum, directly interacts with NK cells that express IL-15R $\beta-\gamma$ chains without transpresentation by presenting cells. (B) Presenting cells directly interact with NK cells via the formation of an immunologic synapse. Then, the mIL-15 complex (membrane-associated IL-15-IL-15R $\alpha$ complex) on presenting cells interacts with the IL-15R $\beta-\gamma$ receptor at the plasma membrane of NK cells to transduce IL-15 signaling. (C) During synapse formation, the mIL-15 complex is cleaved from the plasma membrane and then endocytosed by NK cells. The internalized mIL-15 complex co-localizes with the IL-15R $\beta-\gamma \mathrm{c}$ receptor in the cytoplasm and contributes to IL-15 signaling activation. (D) The intact mlL-15 complex together with the plasma membrane of presenting cells is internalized into NK cells through a distinct process termed transendocytosis without being cleaved. Subsequently, the transendocytosed IL-15R $\alpha-I L-15$ complex colocalizes with the IL$15 \mathrm{R} \beta / \gamma \mathrm{c}$ chain in intracellular NK cell compartments and contributes to IL-15 signaling activation. 
regulatory role of these receptor-ligand interactions in IL-15 signaling remains elusive. In vitro studies have demonstrated that the interaction between inhibitory receptors, such as KIR2DL1, KIR2DL2/3, or CD94-NKG2A, and their cognate ligands selectively inhibited the phosphorylation of AKT and S6 but not Stat5, and this effect was concomitant with reduced proliferation induced by the mIL-15 complex but not the sIL15 complex (79).

During cell-to-cell contact, the membrane-bound IL-15R $\alpha$ IL-15 complex is internalized by NK cells and contributes to the activation of IL-15 signaling (77). This process is dependent on the proteolytic cleavage of IL-15R $\alpha$, which allows the IL-15R $\alpha$ IL-15 complex to separate from the presenting cells. In addition, the IL-15R $\alpha$-IL-15 complex gradually accumulates in NK cells during the interaction between IL-15-presenting cells and NK cells. After separation from the presenting cells, the previously restored IL-15 complex contributes to the survival and residual proliferation of NK cells in a time-limited manner. In contrast, abrogation of IL-15R $\alpha$ cleavage results in enhanced and prolonged Stat5 phosphorylation concomitant with increased IL-15 expression in the synapse. This observation further demonstrated that the mIL-15 complex on presenting cells also contributes to the activation of IL-15 signaling during cell-to-cell contact (77). Therefore, mIL-15 complex cleavage and internalization could represent a negative regulatory mechanism that reduces the availability of transpresented-IL15 and protects NK cell from excessive IL-15 signaling.

However, inhibition of IL-15R $\alpha$ cleavage did not completely abrogate the entry of the IL-15R $\alpha$-IL-15 complex into NK cells, indicating that the IL-15 entry is not exclusively dependent on the shedding of the membrane-associated IL-15R $\alpha$-IL-15 complex (77). Indeed, the intact membrane-associated IL15R $\alpha$-IL-15 complex from the presenting cells together with the plasma membrane of presenting cells is internalized into NK cells through a distinct process termed transendocytosis without being cleaved (73). Subsequently, the transendocytosed IL$15 \mathrm{R} \alpha$-IL-15 complex colocalizes with the IL-15R $\beta / \gamma \mathrm{c}$ chain in intracellular NK cell compartments to promote ribosomal protein S6 phosphorylation and NK cell proliferation. Consistently, interference of transendocytosis by silencing the small GTPase TC21, which is a critical component of transendocytosis, substantially inhibits S6 phosphorylation but not Stat5 phosphorylation in NK cells.

\section{WHAT IS THE DOWNSTREAM TARGET OF IL-15 SIGNALING DURING NK CELL DEVELOPMENT?}

\section{IL-15-JAK-STAT5 Signaling for NK Cell Development}

Upon the engagement of the IL-15R $\alpha$-IL-15 complex with the IL-15R $\beta / \gamma$ c receptor, three distinct signaling pathways, including Ras-MEK-MAPK, JAK-STAT5 and PI3K-ATK-mTOR are activated and contribute to $\mathrm{NK}$ cell development. The
IL-15R $\alpha$-IL-15 complex primarily induces the activation of the JAK-STAT5 pathway via recruiting Janus kinase 1 (JAK1) and JAK3 (Figure 5). Interestingly, JAK1 binding to the IL-2/IL$15 \mathrm{R} \beta$ and JAK3 combining with $\gamma_{\mathrm{c}}$ is crucial for signal transduction by activating JAK1 and JAK3, which induce the phosphorylation of tyrosine residues in IL-2/IL-15 R $\beta$ (80-82). This model has been further confirmed by the discovery that humans with deletion of JAK3 exhibited similar phenotypes of severe combined immunodeficiency (SCID) as $\gamma$ c-deficient patients (83). Although the specific function of JAK1 and JAK3 varies considerably, genetically engineered mice provide the possibility to determine the distinct roles of individual proteins. While deficiency of Jak1 in mice leads to perinatal lethality (84), a remarkable decrease of immature B220+ NK cells was observed in adult mice with inducible loss of Jak1, indicating that Jak1 is essential for NK cell development (85). These observations were recently validated in mice with conditional deletion of Jak1 in Ncr1-expressing cells (Jak $1^{\mathrm{fl} / \mathrm{fl}} \mathrm{Ncr} 1 \mathrm{Cre}$ ), displaying blockade of NK cell development at the NKp and iNK stages in a dose-dependent manner (86). Not surprisingly, JAK3 also plays an important role in NK cell development, coinciding with the finding that Jak3-deficient mice suffer from differentiation block of NK cells at the pre-NKP stage (87). Despite the cooperation of Jak1 and Jak3 in NK cell development, accumulating evidence has proposed that Jak1 plays a dominant role overriding Jak3 during the signal transduction $(88,89)$. The specific inactivity of Jak3 in human cells lines fails to attenuate STAT5 phosphorylation as anticipated, as two Jak kinases have an equivalent function in signal transduction, whereas remarkable abrogated downstream signaling was found in Jak1-inactive cells lines (88). Furthermore, the knockdown experiments suggested that Jak1 is responsible for the phosphorylation of Jak3 and STAT5 after cytokine receptor activation, and Jak3 contributes to enhance Jak1 activity by phosphorylating it. Likewise, quantitative mass spectrometry analysis also revealed that Jak1 is more important that Jak3 in mature NK cells (90). Although, many studies have addressed the vital roles of Jak1 and Jak3 in signal transduction, molecular interactions between the two Jak kinases and their individual contributions in NK cells remain to be determined.

Although it has long been believed that IL-15 signaling is exclusively mediated by JAK1/3, the role of JAK2 in IL- 15 signaling is controversial. Notably, a recent study described that JAK2 phosphorylates STAT5 downstream of IL-15 during NK cell differentiation in vitro (91). Accordingly, mice with conditional deletion of Jak2 in HSC exhibited impaired NK cell maturation (92). However, it has been shown that JAK2 is intrinsically dispensable for NK cell development as mice with conditional deletion of JAK2 in NKp46+ cells exhibited intact NK cell numbers and maturation (86). These discrepancies indicate that the absence of JAK2 may extrinsically interfere in NK cell maturation by altering the cytokine milieu.

The discovery of the IL-15-JAK association has contributed to the finding that members of the signal transducer and activation of transcription (STAT) family directly bind to phosphortyrosine docking site(s) in the IL-2/IL-15R $\beta$ chain and are then 


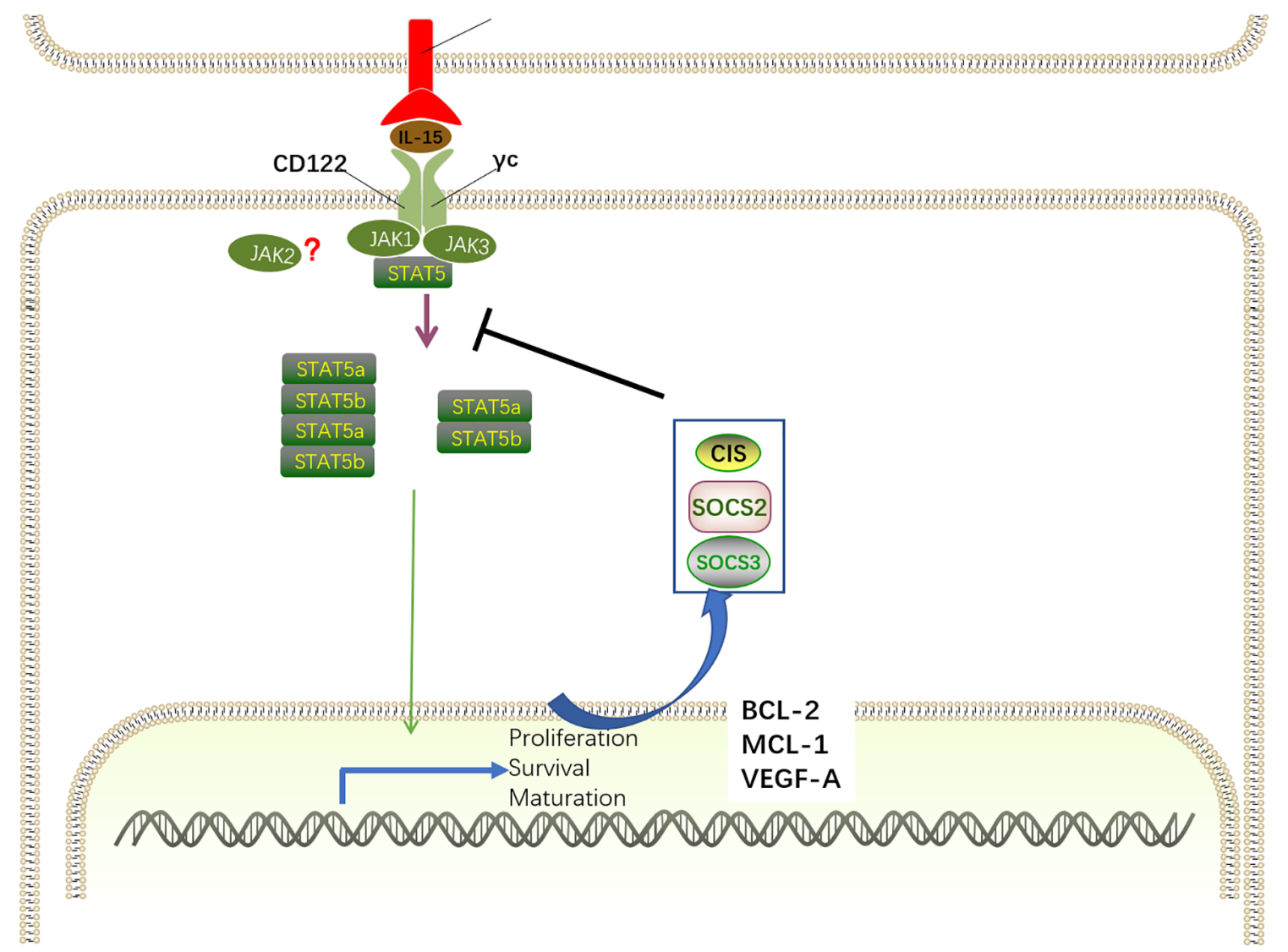

FIGURE 5 | IL-15-JAK-STAT5 signaling for NK cell development. The IL-15R $\alpha-I L-15$ complex primarily induces the activation of the JAK-STAT5 pathway via recruiting JAK1 and JAK3. For signal transduction, JAK1 binds to the IL-2/IL-15R $\beta$ and JAK3 combines with $\gamma$, inducing the recruitment and phosphorylation of STAT5. By oligomerizing into dimers and tetramers, phosphorylated STAT5a and STAT5b translocate into the nucleus to drive the expression of STAT-target genes encoding proteins related with NK cell development, survival, proliferation, and function, including MCL-1, BCL-2, and VEGF-A. Specifically, IL-15-JAK-STAT5 signaling also promotes the transcription of SOCS family members. SOCS proteins comprise a negative feedback loop to retrain the JAK-STAT5-mediated pathway in NK cell development.

phosphorylated by JAK1 and JAK3 on their tyrosine residues (80). Similar with IL-2, IL-15 predominantly induces STAT5 activation, despite the finding that STAT3 and STAT1 can also be activated to a lesser extent (93). STAT5 is comprised by two distinct transcription factors, STAT5a and STAT5b, that have a remarkable degree of sequence homology (approximately 96\%) (94). By oligomerizing into dimers and tetramers, phosphorylated STAT5a and STAT5b translocate into the nucleus to drive the expression of STAT-target genes, which is critical for NK cell development, survival, proliferation, and function (95-97). STAT5 dimers preferentially bind to $\gamma$ interferon-activated sequence (GAS) motifs, whereas STAT5 tetramers are more flexible given the capacity for various nonconsensus GAS motifs (98). Interestingly, Lin and colleagues revealed that STAT5 dimers are sufficient for early NK cell development, proliferation and cytotoxic capacity, whereas STAT5 tetramers are necessary for NK cell maturation and survival through the induction of the anti-apoptotic protein Bcl2 (99).
It is indisputable that STAT5-related transcriptional programs mediated by IL-15 activation are essential for the biological functions of IL-15. The indispensable role of STAT5mediated transcriptional regulation in NK cell development has been highlighted by the finding that NK cell differentiation was abrogated at the NKp stage in Ncr1-iCreTg mice with conditionally deleted STAT5 (100). Consistently, disrupted NK cell maturation and impaired lytic function were observed in humans with STAT5b mutations (101). Therefore, STAT5 downstream of Jak kinases is essential for transducing IL-15 signaling. Despite the largely redundant functions of STAT5a and STAT5b, their distinct roles have been verified in single knockout mice for STAT5a or STAT5b $(102,103)$. Deficiency of STAT5b results in more dramatic defects in NK cell development than deletion of STAT5a, indicating that STAT5b plays a dominant role in NK cell development $(104,105)$. Consistently, transcriptional analysis revealed that the transcripts mediated by STAT5b are more abundant (104). Furthermore, only Stat5b knockout mice exhibit elevated 
transcription of VEGFA, an angiogenic factor that is transcriptionally repressed by STAT5.

Moreover, chromatin immunoprecipitation (ChIP) analysis of STAT5 binding sites revealed that STAT5 directly targets a large number of genes encoding proteins related with NK cell development and function, including ID2, EOMES, T-BET, perforin, granzymes, and IFN- $\gamma$. Additionally, STAT5 can also bind to Mcl-1 and Bcl-2, correlating with the ability of IL-15 to induce the expression of these genes and sustain NK cell survival (97, 106). Overexpression of BCL-2 enables the survival of STAT5-deficient NK cells but has no influence on proliferation, maturation, or effector functions. However, it seems that Mcl1 is more important in promoting NK cell survival than Bcl-2, as IL-15 stimulation maintains NK cell survival when Bcl-2 was inhibited but not when Mcl1 was inactivated (96).

However, STAT5 is not only correlated with transcriptional activation of gene expression, as the repressive effect of STAT5 binding is also present in NK cells. STAT5 has been shown to bind the Vegf-a gene promoter in NK cells, correlating with suppressed expression of the pro-angiogenic factor VEGF-A in mice and humans (106). In vitro studies revealed that STAT5inactive NK cells showed abundant VEGFA expression, and this effect was also confirmed in vivo by increased tumor formation in the absence of STAT5 (106). In line with the observations in mice, tumor-infiltrating NK cells with VEFGA secretion properties promote tumor progression and are associated with poor outcomes in patients (107-109). According to the repressive effects of STAT5 on IL-17 and Bcl6 mRNA expression in T cells $(110,111)$, further research is essential to deepen our understanding of the distinct roles of STAT5 in NK cells.

IL-15 signaling contributes to the induction of suppressor of cytokine signaling (SOCS) family members, including cytokine inducible SH2-containing protein (CIS), SOCS2, and SOCS3, which comprise a negative feedback loop to retrain the IL-15JAK-STAT5-mediated pathway in NK cell development (90, 112). Several studies have demonstrated that STAT5 directly targets the genes of these SOCS proteins $(99,113)$. SH2containing protein (CIS, encoded by Cish gene) directly interacts with JAK1 to mediate the inhibition of its enzymatic activity and proteasomal degradation, thereby constraining JAKSTAT5 signaling. Consistently, mice with CIS ablation exhibit accumulation of terminally differentiated $\mathrm{CD} 27^{-} \mathrm{CD} 11 \mathrm{~b}^{+} \mathrm{NK}$ cells in the BM and spleen, which is associated with the hyperresponsive nature of NK cells to IL-15 (114). By directly interacting with JAK2, SOCS2 attenuated JAK2 activity and the corresponding JAK2-STAT5 signaling to negatively regulate NK cell differentiation (91). Increased NK cell differentiation has been observed in the absence of SOCS2 in vivo and in vitro, whereas the development advantage is reversed after the addition of a JAK2 inhibitor in vitro. In contrast to its effect on murine NK cells, SOCS2 has no influence on IL-15-mediated human NK cell differentiation in vitro but is essential for human NK cell effector function via the regulation of phosphorylated proline-rich tyrosine kinase 2 (Pyk2) (112). These discrepancies may be attributed to different protocols for mouse and human NK cell development in vitro or species differences. Although knockdown of SOCS3 in mice has no impact on NK cell development and maturation (90), a recent study revealed that SOCS3 suppressed IL-15-mediated STAT5 phosphorylation, correlating with the desensitization of NK cells to IL-15 simulation, resulting in disrupted $\mathrm{NK}$ cell terminal differentiation (115).

\section{IL-15-PI3K-AKT-mTOR Signaling for NK Cell Development}

The interaction of IL-15 with its receptor on NK cells also activates the canonical downstream PI3K-AKT-mTOR pathway (Figure 6). Phosphoinositide 3-kinases (PI3Ks) are comprised of three subclasses, including class I, class II, and class III (116). The class I PI3Ks, which predominantly transduce signaling triggered by cytokine receptor, are heterodimeric enzymes that include a regulatory subunit (p85 $\alpha, \mathrm{p} 50 \alpha, \mathrm{p} 55 \alpha$, $\mathrm{p} 85 \beta, \mathrm{p} 55 \gamma$, and $\mathrm{p} 101)$ and a catalytic subunit (p110 $\alpha, \mathrm{p} 110 \beta$, $\mathrm{p} 110 \gamma$, and $\mathrm{p} 110 \delta$ ). Mice exclusively or simultaneously lacking the PI3K subunits P110 $\gamma$ and $\delta$ exhibit severely defective NK cell maturation and total numbers (116-119). Consistently, p110 $\delta$ mutations in patients impair the development and cytotoxic function of $\mathrm{NK}$ cells, leading to severe viremia, whereas rapamycin treatment partially rescues defective NK cells (117). Despite the multiple membranes of PI3Ks, it is unknown which subtypes are required for IL-15 signaling in NK cell development.

PI3K phosphorylates the three positions of the inositol ring of plasma membrane-associated phosphatidylinositol-4,5bisphosphate $[\mathrm{PI}(4,5) \mathrm{P} 2]$ to generate $\mathrm{PI}(3,4,5) \mathrm{P} 3$, which interacts with proteins containing pleckstrin homology $(\mathrm{PH})$ domains, including the serine/threonine kinases phosphoinositide-dependent kinase (PDK1) and protein kinase $\mathrm{B}$ (PKB; also known as AKT), and localizes these proteins to membranes (120). The interaction between PI(3,4,5)P3 and AKT initiates conformational changes in AKT, allowing PDK1 to phosphorylate AKT at threonine 308 for AKT activation (121).

Subsequently, as an important downstream effector of PI3K/ AKT signaling, the mammalian target of rapamycin (mTOR) is activated. mTOR, a serine/threonine protein kinase, includes two components, namely, mTOR complex1 (mTORC1) and mTORC2. Genetic studies have revealed that Raptor and Rictor are important components of mTORC1 and mTORC2, respectively, by defining their downstream substrates (122).

It was proposed that the activation of the IL-15R-PI3KAKT-mTOR signaling cascade is dose-dependent. Specifically, low IL-15 concentrations only activate the phosphorylation of JAK/STAT5 signaling molecules, whereas the PI3K-AKTmTOR pathway is further activated after exposure to high IL15 concentrations (123). PI3K-AKT-mTOR signaling primarily regulates proliferation, differentiation, and maturation as well as NK cell effector function (124). The indispensable role of mTOR in controlling NK cell development was validated in mice with a specific deficiency in mTOR in NK cells in which NK cells almost disappeared in the peripheral organs, and the remaining NK cells 


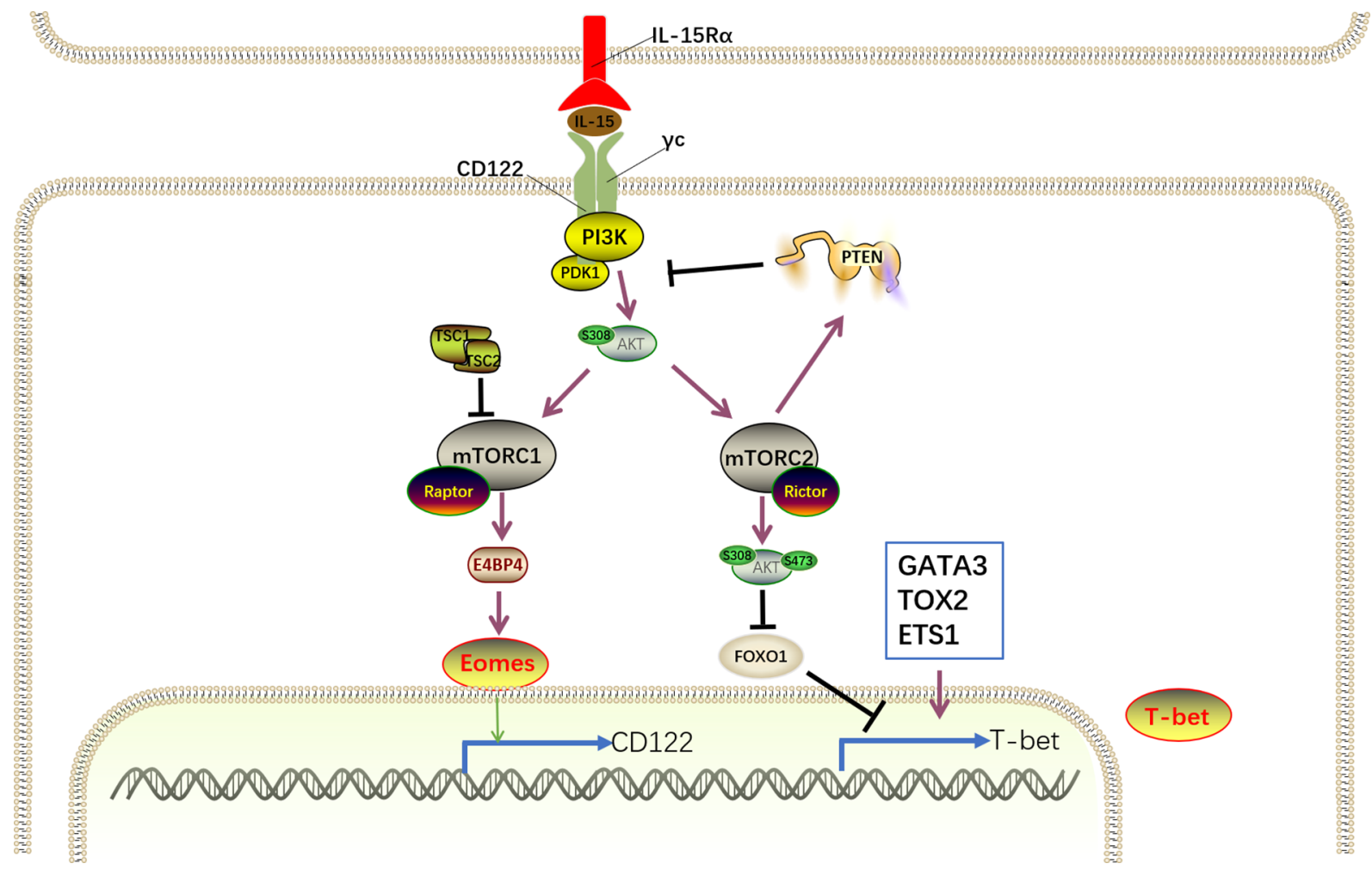

FIGURE 6 | IL-15-PI3K-AKT-mTOR signaling for NK cell development. IL-15 complex interacts with its receptor IL-15R $\beta / \gamma$ on NK cells to trigger PI3K/AKT pathway autophosphorylation and activation and subsequent activation of mTORC1 and mTORC2. mTORC1 and mTORC2 differentially promote NK cell development in a cooperative and non-redundant manner primarily by divergent induction of corresponding transcription factor Eomes and T-bet. Eomes binds to the il2rb promoter and drives CD122 expression to maintain IL-15 responsiveness, generating a positive feedback loop to amplify the IL-15 signaling. Despite the negative regulation of T-bet expression by FoxO1, several transcription factors, including GATA3, TOX2, and ETS-1, promote T-bet expression. However, the activation of mTOR signaling is tightly modulated by cooperation of TSC1 and PTEN.

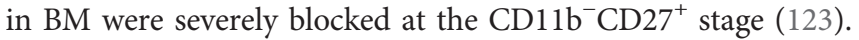
Recent studies have demonstrated that mTORC1 and mTORC2 differentially promote NK cell development in a cooperative and non-redundant manner primarily by divergent induction of corresponding transcription factors, namely, T-bet and Eomes $(33,125)$. Intriguingly, mTORC1 and mTORC2 also positively or negatively regulate NK cell effector function, respectively. $\mathrm{Ncrl} 1^{\text {iCre }}$-mediated ablation of Raptor in mice results in disrupted mTORC1 function, leading to the impaired transition from $\mathrm{CD} 27^{+} \mathrm{CD} 11 \mathrm{~b}^{-}$to $\mathrm{CD} 27^{+} \mathrm{CD} 11 \mathrm{~b}^{+} \mathrm{NK}$ cells and reduced $\mathrm{NK}$ cell function. Conversely, terminal maturation from $\mathrm{CD} 27^{+} \mathrm{CD} 11 \mathrm{~b}^{+}$to $\mathrm{CD} 27^{-} \mathrm{CD} 11 \mathrm{~b}^{+} \mathrm{NK}$ cells is impeded in mice in the absence of Rictor, which is essential for mTORC2 metabolic signaling. However, Rictor-deficient NK cells display enhanced effector function.

E4 promoter-binding protein 4 (E4BP4), encoded by Nfil3 (nuclear factor interleukin-3), is the predominant target downstream of mTORC1 $(33,126)$. Mechanistically, PDK1, a kinase downstream of PI3K, is thought to mediate IL-15triggered mTORC1 and AKT phosphorylation to drive E4BP4 expression during NK cell development (127). Ectopic expression of E4BP4 rescued NK cell developmental defects in mTORC1-inactiavted and PDK1-deficient mice (126-128). Meanwhile, the absence of PDK1 in NK cells results in attenuated IL-15-triggered mTORC1 activation and significantly decreased E4BP4 expression (127). Moreover, the inactivation of mTORC1 diminishes the IL-15-mediated E4BP4 expression. These results suggest that the IL-15-PI3K-PDK1mTORC1 signaling pathway is essential for E4BP4 induction. E4BP4 expression is initiated as early as the CLP stage and highly expressed in the iNK and $\mathrm{mNK}$ stages. Nfil3-/-mice display intact CLP compartment, and the population of NKPs, iNK cells, and $\mathrm{mNK}$ cells significantly reduced in the BM, indicating E4BP4 acts as early as CLP stage via an IL-15-independent manner and is essential for $\mathrm{NK}$ cell commitment. However, Ncr $1^{i C r e}$ mediated deletion of $\mathrm{Nfil3}$ has no effect on $\mathrm{NK}$ cell development (129), indicating that Nfil3 is dispensable for NK cell maturation, and other unknown signaling pathways compensate for the absence of Nfil3.

The induction of E4BP4 promotes the expression of Eomes, which binds to the il2rb promoter and drives CD122 expression to maintain IL-15 responsiveness (35). Mice with depletion of 
PDK1 or Eomes exhibit significant accumulation of $\mathrm{CD} 27^{+} \mathrm{CD} 11 \mathrm{~b}^{-} \mathrm{NK}$ cells but are devoid of terminally mature $\mathrm{CD} 27^{-} \mathrm{CD} 11 \mathrm{~b}^{+} \mathrm{NK}$ cells, and these findings resemble the findings in Raptor-deficient mice $(33,130,131)$. Collectively, the IL-15-PI3K-PDK1-mTORC1-E4BP4-Eomes-CD122 pathway generates a positive feedback loop to amplify IL-15 signaling. However, mTORC1 activation is tightly modulated by Tuberous sclerosis 1 (Tsc1), which exhibits significantly increased expression after long-term IL-15 stimulation and forms a complex with Tsc2 with the aid of AKT (132).

Contrary to the indispensable role of mTORC1 in the early maturation of NK cells, mTORC2 is essential for the terminal maturation of $\mathrm{NK}$ cells from the $\mathrm{CD} 27^{+} \mathrm{CD} 11 \mathrm{~b}^{+}$to the $\mathrm{CD} 27^{-} \mathrm{CD} 11 \mathrm{~b}^{+}$stage. Previous studies have demonstrated that mTORC2 phosphorylates Akt at Serine 473 and augments its kinase activity, leading to the phosphorylation of FoxO1 by Akt $(133,134)$. Akt-triggered phosphorylation promotes modulator protein to interact with FoxO1, thereby inactivating it by blocking DNA binding and accelerating translocation from the nucleus to the cytosol $(33,135)$. This model has been further validated in NK cells through the discovery that mTORC2inactivated NK cells display reduced phosphorylation of $\mathrm{Akt}^{\mathrm{S} 473}$ and FoxO1 (33). In addition, Ingenuity Pathway Analysis (IPA) found a remarkable enrichment of FoxO1 targets in mTORC2-inactivated NK cells. Furthermore, in vitro studies reported that IL-15 efficiently induces phosphorylation, and hence inactivation of FoxO1 in developing NK cells, together with the activation of mTOR signaling $(136,137)$. Based on these results, we speculate that FoxO1 is a direct target of the mTORC2-Akt ${ }^{\mathrm{S} 473}$ signaling axis that exists downstream of IL15 signaling in NK cells. In contrast to the high expression of FoxO1 in NKp and iNKs, the level of FoxO1 is significantly decreased in mNKs (136). Apart from FoxO1, FoxO3 is also expressed by NK cells, although it is maintained at relatively low levels throughout NK cell development. Both Ncr1-Cre -FoxO1 $1^{f l f l}$ and -FoxO1 $1^{f l f l}$ mice exhibit accumulation of terminally differentiated $\mathrm{CD} 27^{-} \mathrm{CD} 11 \mathrm{~b}^{+} \mathrm{NK}$ cells, indicating FoxO1 and FoxO3 redundantly suppress NK cell maturation (137), contradicting the promoting effects of mTORC2. Owing to the weak expression of FoxO3, it is believed that FoxO1 plays a prominent role in $\mathrm{NK}$ cell development. However, in the same Ncr1-Cre -FoxO1 $1^{f l f l}$ mice, Wang et al. reported a remarkable deficiency of iNK and $\mathrm{mNK}$ cells that is attributed to impaired FoxO1-mediated autophagy in iNK cells (136). Therefore, the distinct role of FoxO1 in NK cell development remains to be clearly clarified.

Several studies have demonstrated that the negative regulation of $\mathrm{NK}$ cell development by FoxO1 is associated with suppressed T-bet expression $(33,137)$. In humans, ChIP experiments showed that FoxO1 directly binds to the Tbx21 promoter, promoting decreased T-bet expression. However, in mice, the recruitment of FoxO1 to the $T b \times 21$ proximal promoter region by $\mathrm{Sp} 1$, which is a FoxO1 protein binding partner, resulted in impaired transactivation of $T b \times 21$, leading to disrupted T-bet expression. Consistently, the absence of FoxO1 in NK cells promotes T-bet mRNA and protein expression, whereas T-bet expression is decreased in NK cells with overexpression of FoxO1. In further support of this, Foxo1 and T-bet expression inversely correlate with each other during NK cell maturation. Immature NK cells express high levels of Foxo1, whereas T-bet is present in high amounts in terminally mature NK cells. Furthermore, in contrast to the accelerated maturation of $\mathrm{NK}$ cells in FoxO1 ${ }^{-1-}$ mice, T-bet deficiency abrogated NK cell terminal maturation (40). Taken together, these results demonstrate that decreased levels of FoxO1 are necessary for NK cell maturation by releasing the negative regulation of $\mathrm{T}$-bet.

Despite the negative regulation of T-bet expression by FoxO1, several transcription factors, including GATA binding protein 3 (GATA3), thymocyte selection-associated HMG box 2 (TOX2) and Ets proto-oncogene 1 (ETS-1), promote T-bet expression (138-141). Thus, inactivation of FoxO1 mediated by IL$15^{-} \mathrm{PI} 3 \mathrm{~K}^{-}$mTORC2 signaling coordinated with several transcription factors to promote T-bet expression. T-bet ${ }^{-1}$ mice exhibited remarkably decreased NK cell populations in the periphery, but the NK cell number was modestly elevated in BM (142). This defect is attributed to the decreased expression of S1P5, which is induced by T-bet and responsible for NK cell egress from BM (143). In the absence of T-bet, NK cell maturation is specifically arrested at $\mathrm{CD} 27^{+} \mathrm{CD} 11 \mathrm{~b}^{+}$stage, suggesting that $\mathrm{T}$-bet is essential for $\mathrm{NK}$ cell terminal maturation (60). It has been proposed that T-bet promotes NK cell maturation by transiently inhibiting Eomes expression (36, 142). Consistent with this, T-bet levels are gradually increased during NK cell maturation, accompanied by the decreased expression of Eomes. T-bet also contributes to the induction of Zinc Finger E-box Binding Homeobox 2 (Zeb2) and B lymphocyte-induced maturation protein 1 (Blimp-1), which are critical for NK cell maturation $(36,40,144)$. Thus, the IL15R-PI3K-mTORC2-AKT-FoxO1-T-bet pathway determines the terminal maturation of $\mathrm{NK}$ cells.

In addition, mTORC2 suppresses mTORC1-mediated NK cell effector function by mainly downregulating SLC7A5 expression, which is downstream of STAT5 and regulates mTORC1 activity independent of AKT signaling $(125,145)$. Therefore, mTORC2 counteracts IL-15-mediated mTORC1 hyperactivation to prevent activation-induced NK cell apoptosis. Inversely, mTORC1 maintains IL-15-CD122-IL-15 signaling to sustain mTORC2 activity.

Phosphatase and tensin homolog (PTEN) directly antagonizes the PI3K-AKT pathway by specifically dephosphorylating $\mathrm{PI}(3,4,5) \mathrm{P} 3$, which is downstream of PI3K and functions as an activator for downstream signaling proteins, including Vav, Akt, PDK1, and PI(4,5)P2 (146). Consistently, PTEN suppresses PI3K-AKT signaling and MAPK activation in humans, leading to compromised cytotoxic function (147). Conversely, the PTEN signaling pathway is impaired in Rictordeficient NK cells with an inactive mTORC2 pathway, indicating that mTORC2 promotes PTEN expression to antagonize the PI $(3,4,5) \mathrm{P} 3$-mediated activation of mTORC2 $(33,148)$. Thus, a negative feedback exists between mTORC2 signaling and PTEN expression. 


\section{PERSPECTIVES}

NK cell development is tightly regulated by the interplay between intracellular transcription factors and extracellular signals, such as cognate ligands, chemokines, and cytokines. Notably, pleiotropic cytokine IL-15 is indispensable for the development of NK cells. Recently, immunotherapy has been applied in anticancer and anti-infection treatments. As an important component of immune cell, NK cells have potent cytotoxicity and cytokine production capacity, which allows effective eradication of malignant and infected cells in the absence of graft versus host disease (GVHD). Therefore, NK cells are promising for therapeutic utilization. The prerequisite of clinical application is to substantially expand mature NK cells in vitro. Correspondingly, understanding of the molecular mechanisms by which IL-15 promotes NK cell development and manipulation of IL-15 for proper NK cell expansion in vitro will improve NK cell-based therapeutic strategies (18).

NK cells are the earliest donor-derived lymphocytes recovering after HSCT, whose populations quickly reach donor levels within 1 month $(149,150)$. The well-established reconstitution of NK cells exhibits a protective effect against leukemia relapse and is associated with improved disease-free survival after HSCT (151-153). Although the level of IL-15 is remarkably high after $\mathrm{HSCT}$, the immature $\mathrm{CD} 56^{\text {bright }} \mathrm{KIR}^{-} \mathrm{NK}$ cells dominate the early reconstruction $(149,150)$. Investigating the role of IL-15 in NK cell development after HSCT contributes to better prognosis by intervening NK cell maturation.

Given the formidable efficacy in enhancing NK cell development, IL-15 is much more promising than other cytokines in controlling tumor progression and viral infections.

\section{REFERENCES}

1. Caligiuri MA. Human natural killer cells. Blood (2008) 112(3):461-9. doi: 10.1182/blood-2007-09-077438

2. Koch J, Steinle A, Watzl C, Mandelboim O. Activating natural cytotoxicity receptors of natural killer cells in cancer and infection. Trends Immunol (2013) 34(4):182-91. doi: 10.1016/j.it.2013.01.003

3. Raulet DH, Vance RE. Self-tolerance of natural killer cells. Nat Rev Immunol (2006) 6(7):520-31. doi: 10.1038/nri1863

4. Grabstein KH, Eisenman J, Shanebeck K, Rauch C, Srinivasan S, Fung V, et al. Cloning of a T-Cell Growth-Factor That Interacts with the Beta-Chain of the Interleukin-2 Receptor. Science (1994) 264(5161):965-8. doi: 10.1126/ science. 8178155

5. Fehniger TA, Caligiuri MA. Interleukin 15: biology and relevance to human disease. Blood (2001) 97(1):14-32. doi: 10.1182/blood.v97.1.14

6. Giri JG, Anderson DM, Kumaki S, Park LS, Grabstein KH, Cosman D. Il-15, a Novel T-Cell Growth-Factor That Shares Activities and Receptor Components with Il-2. J Leukocyte Biol (1995) 57(5):763-6. doi: 10.1002/ jlb.57.5.763

7. Giri JG, Kumaki S, Ahdieh M, Friend DJ, Loomis A, Shanebeck K, et al. Identification and Cloning of a Novel Il-15 Binding-Protein That Is Structurally Related to the Alpha-Chain of the Il-2 Receptor. EMBO J (1995) 14(15):3654-63. doi: 10.1002/j.1460-2075.1995.tb00035.x

8. Dubois S, Mariner J, Waldmann TA, Tagaya Y. IL-15Ralpha recycles and presents IL-15 In trans to neighboring cells. Immunity (2002) 17(5):537-47. doi: 10.1016/s1074-7613(02)00429-6

9. Lodolce JP, Burkett PR, Boone DL, Chien M, Ma A. T cell-independent interleukin 15Ralpha signals are required for bystander proliferation. J Exp Med (2001) 194(8):1187-94. doi: 10.1084/jem.194.8.1187
Several murine immunotherapy trials have demonstrated that the administration of IL-15 efficiently drove the expansion and activation of $\mathrm{NK}$ cells and $\mathrm{CD} 8+\mathrm{T}$ cells in vivo, without stimulating the expansion of regulatory $\mathrm{T}$ cells which exert an immunosuppressive effect (154-156). However, due to its adverse effects, such as toxicities, hypotension, thrombocytopenia, IL-15 application was constrained (157). More basic research is required to optimize the structure of IL-15 before it can extended to clinical practice.

\section{AUTHOR CONTRIBUTIONS}

XW wrote the manuscript. X-YZ outlined the manuscript and made a deep intellectual contribution to the work. All authors contributed to the article and approved the submitted version.

\section{FUNDING}

This study was supported by the National Key Research and Development Program of China (No. 2017YFA0104500), the National Natural Science Foundation of China (Nos. 81870140, 82070184), the Innovative Research Groups of the National Natural Science Foundation of China (No. 81621001), and Clinical Medicine Plus X - Young Scholars Project of Peking University (No. PKU2020LCXQ015) supported by "the Fundamental Research Funds for the Central Universities", and Peking University People's Hospital Research and Development Funds (No. RDX2019-14).

10. Castillo EF, Stonier SW, Frasca L, Schluns KS. Dendritic cells support the in vivo development and maintenance of NK cells via IL-15 transpresentation. J Immunol (2009) 183(8):4948-56. doi: 10.4049/ jimmunol.0900719

11. Schluns KS, Nowak EC, Cabrera-Hernandez A, Puddington L, Lefrancois L, Aguila HL. Distinct cell types control lymphoid subset development by means of IL-15 and IL-15 receptor alpha expression. Proc Natl Acad Sci USA (2004) 101(15):5616-21. doi: 10.1073/pnas.0307442101

12. Di Santo JP. NATURAL KILLER CELL DEVELOPMENTAL PATHWAYS: A Question of Balance. Annu Rev Immunol (2006) 24(1):257-86. doi: 10.1146/annurev.immunol.24.021605.090700

13. Stabile H, Fionda C, Santoni A, Gismondi A. Impact of bone marrowderived signals on NK cell development and functional maturation. Cytokine Growth Factor Rev (2018) 42:13-9. doi: 10.1016/j.cytogfr.2018.03.008

14. Kennedy MK, Glaccum M, Brown SN, Butz EA, Viney JL, Embers M, et al. Reversible defects in natural killer and memory CD8 T cell lineages in interleukin 15-deficient mice. J Exp Med (2000) 191(5):771-80. doi: 10.1084/ jem.191.5.771

15. Lodolce JP, Boone DL, Chai S, Swain RE, Dassopoulos T, Trettin S, et al. IL15 receptor maintains lymphoid homeostasis by supporting lymphocyte homing and proliferation. Immunity (1998) 9(5):669-76. doi: 10.1016/ s1074-7613(00)80664-0

16. Vosshenrich CA, Ranson T, Samson SI, Corcuff E, Colucci F, Rosmaraki EE, et al. Roles for common cytokine receptor gamma-chain-dependent cytokines in the generation, differentiation, and maturation of NK cell precursors and peripheral NK cells in vivo. J Immunol (2005) 174 (3):1213-21. doi: 10.4049/jimmunol.174.3.1213

17. Suzuki H, Duncan GS, Takimoto H, Mak TW. Abnormal development of intestinal intraepithelial lymphocytes and peripheral natural killer cells in 
mice lacking the IL-2 receptor beta chain. J Exp Med (1997) 185(3):499-505. doi: $10.1084 / \mathrm{jem} .185 .3 .499$

18. Mrózek E, Anderson P, Caligiuri MA. Role of interleukin-15 in the development of human CD56+ natural killer cells from CD34+ hematopoietic progenitor cells. Blood (1996) 87(7):2632-40. doi: 10.1182/ blood.V87.7.2632.bloodjournal8772632

19. Yu H, Fehniger TA, Fuchshuber P, Thiel KS, Vivier E, Carson WE, et al. Flt3 ligand promotes the generation of a distinct CD34(+) human natural killer cell progenitor that responds to interleukin-15. Blood (1998) 92(10):364757. doi: 10.1182/blood.V92.10.3647.422k43_3647_3657

20. Huntington ND, Legrand N, Alves NL, Jaron B, Weijer K, Plet A, et al. IL-15 trans-presentation promotes human NK cell development and differentiation in vivo. J Exp Med (2009) 206(1):25-34. doi: 10.1084/ jem. 20082013

21. Sun JC, Ma A, Lanier LL. Cutting edge: IL-15-independent NK cell response to mouse cytomegalovirus infection. J Immunol (2009) 183(5):2911-4. doi: 10.4049/jimmunol.0901872

22. Vosshenrich CAJ, Di Santo JP. Developmental programming of natural killer and innate lymphoid cells. Curr Opin Immunol (2013) 25(2):130-8. doi: 10.1016/j.coi.2013.02.002

23. Fathman JW, Bhattacharya D, Inlay MA, Seita J, Karsunky H, Weissman IL. Identification of the earliest natural killer cell-committed progenitor in murine bone marrow. Blood (2011) 118(20):5439. doi: 10.1182/blood-201104-348912

24. Rosmaraki EE, Douagi I, Roth C, Colucci F, Cumano A, Di Santo JP. Identification of committed NK cell progenitors in adult murine bone marrow. Eur J Immunol (2001) 31(6):1900-9. doi: 10.1002/1521-4141 (200106)31:6<1900::aid-immu1900>3.0.co;2-m

25. McCullar V, Oostendorp R, Panoskaltsis-Mortari A, Yun G, Lutz CT, Wagner JE, et al. Mouse fetal and embryonic liver cells differentiate human umbilical cord blood progenitors into CD56-negative natural killer cell precursors in the absence of interleukin-15. Exp Hematol (2008) 36 (5):598-608. doi: 10.1016/j.exphem.2008.01.001

26. Rautela J, Huntington ND. IL-15 signaling in NK cell cancer immunotherapy. Curr Opin Immunol (2017) 44:1-6. doi: 10.1016/ j.coi.2016.10.004

27. Poli A, Michel T, Thérésine M, Andrès E, Hentges F, Zimmer J. CD56bright natural killer (NK) cells: an important NK cell subset. Immunology (2009) 126(4):458-65. doi: 10.1111/j.1365-2567.2008.03027.x

28. Michel T, Poli A, Cuapio A, Briquemont B, Iserentant G, Ollert M, et al. Human CD56bright NK Cells: An Update. J Immunol (2016) 196(7):2923-31. doi: 10.4049/jimmunol.1502570

29. Lima M, Teixeira MA, Queirós ML, Leite M, Santos AH, Justiça B, et al. Immunophenotypic characterization of normal blood CD56+lo versus CD56+hi NK-cell subsets and its impact on the understanding of their tissue distribution and functional properties. Blood Cells Mol Dis (2001) 27 (4):731-43. doi: 10.1006/bcmd.2001.0443

30. Cooper MA, Fehniger TA, Turner SC, Chen KS, Ghaheri BA, Ghayur T, et al. Human natural killer cells: a unique innate immunoregulatory role for the CD56(bright) subset. Blood (2001) 97(10):3146-51. doi: 10.1182/ blood.v97.10.3146

31. Vitale M, Della Chiesa M, Carlomagno S, Romagnani C, Thiel A, Moretta L, et al. The small subset of CD56brightCD16- natural killer cells is selectively responsible for both cell proliferation and interferon-gamma production upon interaction with dendritic cells. Eur J Immunol (2004) 34(6):1715-22. doi: $10.1002 /$ eji. 200425100

32. Lopez-Vergès S, Milush JM, Pandey S, York VA, Arakawa-Hoyt J, Pircher H, et al. CD57 defines a functionally distinct population of mature NK cells in the human CD56dimCD16+ NK-cell subset. Blood (2010) 116(19):3865-74. doi: 10.1182/blood-2010-04-282301

33. Yang C, Tsaih SW, Lemke A, Flister MJ, Thakar MS, Malarkannan S. mTORC1 and mTORC2 differentially promote natural killer cell development. Elife (2018) 7:e35619. doi: 10.7554/eLife.35619

34. Ohno S-i, Sato T, Kohu K, Takeda K, Okumura K, Satake M, et al. Runx proteins are involved in regulation of CD122, Ly49 family and IFN-gamma expression during NK cell differentiation. Int Immunol (2008) 20(1):71-9. doi: $10.1093 /$ intimm/dxm120
35. Intlekofer AM, Takemoto N, Wherry EJ, Longworth SA, Northrup JT, Palanivel VR, et al. Effector and memory CD8(+) T cell fate coupled by Tbet and eomesodermin. Nat Immunol (2005) 6(12):1236-44. doi: 10.1038/ ni1268

36. Gordon SM, Chaix J, Rupp LJ, Wu J, Madera S, Sun JC, et al. The transcription factors T-bet and Eomes control key checkpoints of natural killer cell maturation. Immunity (2012) 36(1):55-67. doi: 10.1016/ j.immuni.2011.11.016

37. Wagner JA, Wong P, Schappe T, Berrien-Elliott MM, Cubitt C, Jaeger N, et al. Stage-Specific Requirement for Eomes in Mature NK Cell Homeostasis and Cytotoxicity. Cell Rep (2020) 31(9):107720. doi: 10.1016/ j.celrep.2020.107720

38. Daussy C, Faure F, Mayol K, Viel S, Gasteiger G, Charrier E, et al. T-bet and Eomes instruct the development of two distinct natural killer cell lineages in the liver and in the bone marrow. J Exp Med (2014) 211(3):563-77. doi: $10.1084 /$ jem.20131560

39. Colonna M. Innate Lymphoid Cells: Diversity, Plasticity, and Unique Functions in Immunity. Immunity (2018) 48(6):1104-17. doi: 10.1016/ j.immuni.2018.05.013

40. van Helden MJ, Goossens S, Daussy C, Mathieu AL, Faure F, Marçais A, et al. Terminal NK cell maturation is controlled by concerted actions of Tbet and Zeb2 and is essential for melanoma rejection. J Exp Med (2015) 212 (12):2015-25. doi: 10.1084/jem.20150809

41. Bamford RN, Battiata AP, Burton JD, Sharma H, Waldmann TA. Interleukin (IL) $15 / \mathrm{IL}-\mathrm{T}$ production by the adult T-cell leukemia cell line HuT-102 is associated with a human T-cell lymphotrophic virus type I R region/IL-15 fusion message that lacks many upstream AUGs that normally attenuate IL15 mRNA translation. Proc Natl Acad Sci USA (1996) 93(7):2897-902. doi: 10.1073/pnas.93.7.2897

42. Bamford RN, DeFilippis AP, Azimi N, Kurys G, Waldmann TA. The 5 untranslated region, signal peptide, and the coding sequence of the carboxyl terminus of IL-15 participate in its multifaceted translational control. J Immunol (1998) 160(9):4418-26.

43. Gaggero A, Azzarone B, Andrei C, Mishal Z, Meazza R, Zappia E, et al. Differential intracellular trafficking, secretion and endosomal localization of two IL-15 isoforms. Eur J Immunol (1999) 29(4):1265-74. doi: 10.1002/(sici) 1521-4141(199904)29:04<1265::Aid-immu1265>3.0.Co;2-v

44. Tagaya Y, Kurys G, Thies TA, Losi JM, Azimi N, Hanover JA, et al. Generation of secretable and nonsecretable interleukin 15 isoforms through alternate usage of signal peptides. Proc Natl Acad Sci USA (1997) 94(26):14444-9. doi: 10.1073/pnas.94.26.14444

45. Meazza R, Gaggero A, Neglia F, Basso S, Sforzini S, Pereno R, et al. Expression of two interleukin-15 mRNA isoforms in human tumors does not correlate with secretion: role of different signal peptides. Eur J Immunol (1997) 27(5):1049-54. doi: 10.1002/eji.1830270502

46. Kurys G, Tagaya Y, Bamford R, Hanover JA, Waldmann TA. The long signal peptide isoform and its alternative processing direct the intracellular trafficking of interleukin-15. J Biol Chem (2000) 275(39):30653-9. doi: $10.1074 /$ jbc.M002373200

47. Colpitts SL, Stoklasek TA, Plumlee CR, Obar JJ, Guo C, Lefrançois L. Cutting edge: the role of IFN- $\alpha$ receptor and MyD88 signaling in induction of IL-15 expression in vivo. J Immunol (2012) 188(6):2483-7. doi: 10.4049/ jimmunol.1103609

48. Colpitts SL, Stonier SW, Stoklasek TA, Root SH, Aguila HL, Schluns KS, et al. Transcriptional regulation of IL-15 expression during hematopoiesis. J Immunol (2013) 191(6):3017-24. doi: 10.4049/jimmunol.1301389

49. Cui G, Hara T, Simmons S, Wagatsuma K, Abe A, Miyachi H, et al. Characterization of the IL-15 niche in primary and secondary lymphoid organs in vivo. Proc Natl Acad Sci USA (2014) 111(5):1915-20. doi: 10.1073/ pnas. 1318281111

50. Sugiyama T, Kohara H, Noda M, Nagasawa T. Maintenance of the hematopoietic stem cell pool by CXCL12-CXCR4 chemokine signaling in bone marrow stromal cell niches. Immunity (2006) 25(6):977-88. doi: $10.1016 /$ j.immuni.2006.10.016

51. Noda M, Omatsu Y, Sugiyama T, Oishi S, Fujii N, Nagasawa T. CXCL12CXCR4 chemokine signaling is essential for NK-cell development in adult mice. Blood (2011) 117(2):451-8. doi: 10.1182/blood-2010-04-277897 
52. Zhang XH, Sun SQ, Hwang IK, Tough DF, Sprent J. Potent and selective stimulation of memory-phenotype $\mathrm{CD} 8(+) \mathrm{T}$ cells in vivo by IL-15. Immunity (1998) 8(5):591-9. doi: 10.1016/S1074-7613(00) 80564-6

53. Xie CB, Jiang B, Qin L, Tellides G, Kirkiles-Smith NC, Jane-Wit D, et al. Complement-activated interferon- $\gamma$-primed human endothelium transpresents interleukin-15 to CD8+ T cells. J Clin Invest (2020) 130 (7):3437-52. doi: 10.1172/jci135060

54. Oppenheimer-Marks N, Brezinschek RI, Mohamadzadeh M, Vita R, Lipsky PE. Interleukin 15 is produced by endothelial cells and increases the transendothelial migration of T cells In vitro and in the SCID mouse-human rheumatoid arthritis model In vivo. J Clin Invest (1998) 101(6):1261-72. doi: $10.1172 /$ jci1986

55. Mattei F, Schiavoni G, Belardelli F, Tough DF. IL-15 is expressed by dendritic cells in response to type IIFN, double-stranded RNA, or lipopolysaccharide and promotes dendritic cell activation. I Immunol (2001) 167(3):1179-87. doi: 10.4049/jimmunol.167.3.1179

56. Nolz JC, Richer MJ. Control of memory CD8(+) T cell longevity and effector functions by IL-15. Mol Immunol (2020) 117:180-8. doi: 10.1016/ j.molimm.2019.11.011

57. Anthony SM, Rivas SC, Colpitts SL, Howard ME, Stonier SW, Schluns KS. Inflammatory Signals Regulate IL-15 in Response to Lymphodepletion. J Immunol (2016) 196(11):4544-52. doi: 10.4049/jimmunol.1600219

58. Soudja SM, Ruiz AL, Marie JC, Lauvau G. Inflammatory monocytes activate memory CD8(+) T and innate NK lymphocytes independent of cognate antigen during microbial pathogen invasion. Immunity (2012) 37(3):549-62. doi: 10.1016/j.immuni.2012.05.029

59. Carrero RMS, Beceren-Braun F, Rivas SC, Hegde SM, Gangadharan A, Plote $\mathrm{D}$, et al. IL-15 is a component of the inflammatory milieu in the tumor microenvironment promoting antitumor responses. Proc Natl Acad Sci USA (2019) 116(2):599-608. doi: 10.1073/pnas.1814642116

60. Soderquest K, Powell N, Luci C, van Rooijen N, Hidalgo A, Geissmann F, et al. Monocytes control natural killer cell differentiation to effector phenotypes. Blood (2011) 117(17):4511-8. doi: 10.1182/blood-2010-10312264

61. Mortier E, Advincula R, Kim L, Chmura S, Barrera J, Reizis B, et al. Macrophage- and dendritic-cell-derived interleukin-15 receptor alpha supports homeostasis of distinct CD8+ T cell subsets. Immunity (2009) 31 (5):811-22. doi: 10.1016/j.immuni.2009.09.017

62. Gil-Cruz C, Perez-Shibayama C, Onder L, Chai Q, Cupovic J, Cheng HW, et al. Fibroblastic reticular cells regulate intestinal inflammation via IL-15mediated control of group 1 ILCs. Nat Immunol (2016) 17(12):1388-96. doi: $10.1038 /$ ni.3566

63. Briard D, Brouty-Boyé D, Azzarone B, Jasmin C. Fibroblasts from human spleen regulate NK cell differentiation from blood CD34(+) progenitors via cell surface IL-15. J Immunol (2002) 168(9):4326-32. doi: 10.4049/ jimmunol.168.9.4326

64. Stonier SW, Schluns KS. Trans-presentation: a novel mechanism regulating IL-15 delivery and responses. Immunol Lett (2010) 127(2):85-92. doi: 10.1016/j.imlet.2009.09.009

65. Bergamaschi C, Rosati M, Jalah R, Valentin A, Kulkarni V, Alicea C, et al. Intracellular interaction of interleukin-15 with its receptor alpha during production leads to mutual stabilization and increased bioactivity. J Biol Chem (2008) 283(7):4189-99. doi: 10.1074/jbc.M705725200

66. Sandau MM, Schluns KS, Lefrancois L, Jameson SC. Cutting edge: transpresentation of IL-15 by bone marrow-derived cells necessitates expression of IL-15 and IL-15R alpha by the same cells. J Immunol (2004) 173(11):6537-41. doi: 10.4049/jimmunol.173.11.6537

67. Burkett PR, Koka R, Chien M, Chai S, Boone DL, Ma A. Coordinate expression and trans presentation of interleukin (IL)-15Ralpha and IL-15 supports natural killer cell and memory CD8+ T cell homeostasis. J Exp Med (2004) 200(7):825-34. doi: 10.1084/jem.20041389

68. Mortier E, Woo T, Advincula R, Gozalo S, Ma A. IL-15Ralpha chaperones IL-15 to stable dendritic cell membrane complexes that activate NK cells via trans presentation. J Exp Med (2008) 205(5):1213-25. doi: 10.1084/ jem.20071913

69. Anthony SM, Howard ME, Hailemichael Y, Overwijk WW, Schluns KS. Soluble interleukin-15 complexes are generated in vivo by type I interferon dependent and independent pathways. PloS One (2015) 10(3):e0120274. doi: 10.1371/journal.pone.0120274

70. Bergamaschi C, Bear J, Rosati M, Beach RK, Alicea C, Sowder R, et al. Circulating IL-15 exists as heterodimeric complex with soluble IL-15R $\alpha$ in human and mouse serum. Blood (2012) 120(1):e1-8. doi: 10.1182/blood2011-10-384362

71. Stoklasek TA, Schluns KS, Lefrançois L. Combined IL-15/IL-15Ralpha immunotherapy maximizes IL-15 activity in vivo. J Immunol (2006) 177 (9):6072-80. doi: 10.4049/jimmunol.177.9.6072

72. Rubinstein MP, Kovar M, Purton JF, Cho JH, Boyman O, Surh CD, et al. Converting IL-15 to a superagonist by binding to soluble IL-15R \{alpha\}. Proc Natl Acad Sci USA (2006) 103(24):9166-71. doi: 10.1073/ pnas.0600240103

73. Anton OM, Peterson ME, Hollander MJ, Dorward DW, Arora G, Traba J, et al. Trans-endocytosis of intact IL-15R $\alpha$-IL-15 complex from presenting cells into NK cells favors signaling for proliferation. Proc Natl Acad Sci USA (2020) 117(1):522-31. doi: 10.1073/pnas.1911678117

74. Sato N, Patel HJ, Waldmann TA, Tagaya Y. The IL-15/IL-15Ralpha on cell surfaces enables sustained IL-15 activity and contributes to the long survival of CD8 memory T cells. Proc Natl Acad Sci USA (2007) 104(2):588-93. doi: 10.1073/pnas.0610115104

75. Koka R, Burkett PR, Chien M, Chai S, Chan F, Lodolce JP, et al. Interleukin (IL)-15R[alpha]-deficient natural killer cells survive in normal but not IL15R[alpha]-deficient mice. J Exp Med (2003) 197(8):977-84. doi: 10.1084/ jem.20021836

76. Kawamura T, Koka R, Ma A, Kumar V. Differential roles for IL-15R alphachain in NK cell development and Ly-49 induction. J Immunol (2003) 171 (10):5085-90. doi: 10.4049/jimmunol.171.10.5085

77. Tamzalit F, Barbieux I, Plet A, Heim J, Nedellec S, Morisseau S, et al. IL15.IL-15R $\alpha$ complex shedding following trans-presentation is essential for the survival of IL-15 responding NK and T cells. Proc Natl Acad Sci USA (2014) 111(23):8565-70. doi: 10.1073/pnas.1405514111

78. Brilot F, Strowig T, Roberts SM, Arrey F, Münz C. NK cell survival mediated through the regulatory synapse with human DCs requires IL-15Ralpha. J Clin Invest (2007) 117(11):3316-29. doi: 10.1172/jci31751

79. Anton OM, Vielkind S, Peterson ME, Tagaya Y, Long EO. NK Cell Proliferation Induced by IL-15 Transpresentation Is Negatively Regulated by Inhibitory Receptors. J Immunol (2015) 195(10):4810-21. doi: 10.4049/ jimmunol.1500414

80. Leonard WJ, O'Shea JJ. JAKS AND STATS: Biological implications. Annu Rev Immunol (1998) 16:293-322. doi: 10.1146/annurev.immunol.16.1.293

81. Nakamura Y, Russell SM, Mess SA, Friedmann M, Erdos M, Francois C, et al. Heterodimerization of the Il-2 Receptor Beta-Chain and GammaChain Cytoplasmic Domains Is Required for Signaling. Nature (1994) 369 (6478):330-3. doi: 10.1038/369330a0

82. Nelson BH, Lord JD, Greenberg PD. Cytoplasmic Domains of the Interleukin-2 Receptor Beta-Chain and Gamma-Chain Mediate the Signal for T-Cell Proliferation. Nature (1994) 369(6478):333-6. doi: 10.1038/ 369333a0

83. Macchi P, Villa A, Giliani S, Sacco MG, Frattini A, Porta F, et al. Mutations of Jak-3 gene in patients with autosomal severe combined immune deficiency (SCID). Nature (1995) 377(6544):65-8. doi: 10.1038/377065a0

84. Rodig SJ, Meraz MA, White JM, Lampe PA, Riley JK, Arthur CD, et al. Disruption of the Jak1 gene demonstrates obligatory and nonredundant roles of the Jaks in cytokine-induced biologic responses. Cell (1998) 93 (3):373-83. doi: 10.1016/s0092-8674(00)81166-6

85. Kleppe M, Spitzer MH, Li S, Hill CE, Dong L, Papalexi E, et al. Jak1 Integrates Cytokine Sensing to Regulate Hematopoietic Stem Cell Function and Stress Hematopoiesis. Cell Stem Cell (2017) 21(4):489-+. doi: 10.1016/ j.stem.2017.08.011

86. Witalisz-Siepracka A, Klein K, Prinz D, Leidenfrost N, Schabbauer G, Dohnal A, et al. Loss of JAK1 Drives Innate Immune Deficiency. Front Immunol (2018) 9:3108. doi: 10.3389/fimmu.2018.03108

87. Robinette ML, Cella M, Telliez JB, Ulland TK, Barrow AD, Capuder K, et al. Jak3 deficiency blocks innate lymphoid cell development. Mucosal Immunol (2018) 11(1):50-60. doi: 10.1038/mi.2017.38

88. Haan C, Rolvering C, Raulf F, Kapp M, Druckes P, Thoma G, et al. Jak1 Has a Dominant Role over Jak3 in Signal Transduction through gamma 
c-Containing Cytokine Receptors. Chem Biol (2011) 18(3):314-23. doi: 10.1016/j.chembiol.2011.01.012

89. Liu KD, Gaffen SL, Goldsmith MA, Greene WC. Janus kinases in interleukin-2-mediated signaling: JAK1 and JAK3 are differentially regulated by tyrosine phosphorylation. Curr Biol (1997) 7(11):817-26. doi: 10.1016/s0960-9822(06)00369-1

90. Delconte RB, Kolesnik TB, Dagley LF, Rautela J, Shi W, Putz EM, et al. CIS is a potent checkpoint in NK cell-mediated tumor immunity. Nat Immunol (2016) 17(7):816-24. doi: 10.1038/ni.3470

91. Kim WS, Kim MJ, Kim DO, Byun JE, Huy H, Song HY, et al. Suppressor of Cytokine Signaling 2 Negatively Regulates NK Cell Differentiation by Inhibiting JAK2 Activity. Sci Rep (2017) 7:46153. doi: 10.1038/srep46153 doi: ARTN 46153

92. Bottos A, Gotthardt D, Gill JW, Gattelli A, Frei A, Tzankov A, et al. Decreased NK-cell tumour immunosurveillance consequent to JAK inhibition enhances metastasis in breast cancer models. Nat Commun (2016) 7:12258. doi: 10.1038/ncomms12258 doi: ARTN 12258.

93. Lin JX, Migone TS, Tsang M, Friedmann M, Weatherbee JA, Zhou L, et al. The role of shared receptor motifs and common Stat proteins in the generation of cytokine pleiotropy and redundancy by IL-2, IL-4, IL-7, IL13, and IL-15. Immunity (1995) 2(4):331-9. doi: 10.1016/1074-7613(95) 90141-8

94. Lin JX, Leonard WJ. The role of Stat5a and Stat5b in signaling by IL-2 family cytokines. Oncogene (2000) 19(21):2566-76. doi: 10.1038/sj.onc.1203523

95. Huntington ND. The unconventional expression of IL-15 and its role in NK cell homeostasis. Immunol Cell Biol (2014) 92(3):210-3. doi: 10.1038/ icb.2014.1

96. Huntington ND, Puthalakath H, Gunn P, Naik E, Michalak EM, Smyth MJ, et al. Interleukin 15-mediated survival of natural killer cells is determined by interactions among Bim, Noxa and Mcl-1. Nat Immunol (2007) 8(8):856-63. doi: $10.1038 /$ nil 1487

97. Sathe P, Delconte RB, Souza-Fonseca-Guimaraes F, Seillet C, Chopin M, Vandenberg CJ, et al. Innate immunodeficiency following genetic ablation of Mcl1 in natural killer cells. Nat Commun (2014) 5:4539. doi: 10.1038/ ncomms 5539

98. Soldaini E, John S, Moro S, Bollenbacher J, Schindler U, Leonard WJ. DNA binding site selection of dimeric and tetrameric Stat5 proteins reveals a large repertoire of divergent tetrameric Stat5a binding sites. Mol Cell Biol (2000) 20(1):389-401. doi: 10.1128/mcb.20.1.389-401.2000

99. Lin JX, Du N, Li P, Kazemian M, Gebregiorgis T, Spolski R, et al. Critical functions for STAT5 tetramers in the maturation and survival of natural killer cells. Nat Commun (2017) 8(1):1320. doi: 10.1038/s41467-017-01477-5

100. Eckelhart E, Warsch W, Zebedin E, Simma O, Stoiber D, Kolbe T, et al. A novel Ncr1-Cre mouse reveals the essential role of STAT5 for NK-cell survival and development. Blood (2011) 117(5):1565-73. doi: 10.1182/ blood-2010-06-291633

101. Vargas-Hernández A, Witalisz-Siepracka A, Prchal-Murphy M, Klein K, Mahapatra S, Al-Herz W, et al. Human signal transducer and activator of transcription 5b (STAT5b) mutation causes dysregulated human natural killer cell maturation and impaired lytic function. J Allergy Clin Immunol (2020) 145(1):345-357.e349. doi: 10.1016/j.jaci.2019.09.016

102. Liu XW, Robinson GW, Wagner KU, Garrett L, WynshawBoris A, Hennighausen L. Stat5a is mandatory for adult mammary gland development and lactogenesis. Gene Dev (1997) 11(2):179-86. doi: 10.1101/gad.11.2.179

103. Wakao H, Gouilleux F, Groner B. Mammary-Gland Factor (Mgf) Is a Novel Member of the Cytokine Regulated Transcription Factor Gene Family and Confers the Prolactin Response. EMBO J (1994) 13(9):2182-91. doi: 10.1002/ j.1460-2075.1994.tb06495.x

104. Villarino AV, Sciume G, Davis FP, Iwata S, Zitti B, Robinson GW, et al. Subset-and tissue-defined STAT5 thresholds control homeostasis and function of innate lymphoid cells. J Exp Med (2017) 214(10):2999-3014. doi: 10.1084/jem.20150907

105. Imada K, Bloom ET, Nakajima H, Horvath-Arcidiacono JA, Udy GB, Davey HW, et al. Stat5b is essential for natural killer cell-mediated proliferation and cytolytic activity. J Exp Med (1998) 188(11):2067-74. doi: 10.1084/jem.188.11.2067

106. Gotthardt D, Putz EM, Grundschober E, Prchal-Murphy M, Straka E, Kudweis P, et al. STAT5 Is a Key Regulator in NK Cells and Acts as a
Molecular Switch from Tumor Surveillance to Tumor Promotion. Cancer Discovery (2016) 6(4):414-29. doi: 10.1158/2159-8290.Cd-15-0732

107. Bruno A, Focaccetti C, Pagani A, Imperatori AS, Spagnoletti M, Rotolo N, et al. The proangiogenic phenotype of natural killer cells in patients with non-small cell lung cancer. Neoplasia (2013) 15(2):133-42. doi: 10.1593/ neo. 121758

108. Levi I, Amsalem H, Nissan A, Darash-Yahana M, Peretz T, Mandelboim O, et al. Characterization of tumor infiltrating natural killer cell subset. Oncotarget (2015) 6(15):13835-43. doi: 10.18632/oncotarget.3453

109. Bruno A, Ferlazzo G, Albini A, Noonan DM. A think tank of TINK/TANKs: tumor-infiltrating/tumor-associated natural killer cells in tumor progression and angiogenesis. J Natl Cancer Inst (2014) 106(8):dju200. doi: 10.1093/jnci/ dju200

110. Yang XP, Ghoreschi K, Steward-Tharp SM, Rodriguez-Canales J, Zhu J, Grainger JR, et al. Opposing regulation of the locus encoding IL-17 through direct, reciprocal actions of STAT3 and STAT5. Nat Immunol (2011) 12 (3):247-54. doi: 10.1038/ni.1995

111. Villarino A, Laurence A, Robinson GW, Bonelli M, Dema B, Afzali B, et al. Signal transducer and activator of transcription 5 (STAT5) paralog dose governs $\mathrm{T}$ cell effector and regulatory functions. Elife (2016) 5:e08384. doi: 10.7554/eLife.08384

112. Lee SH, Yun S, Piao ZH, Jeong M, Kim DO, Jung H, et al. Suppressor of cytokine signaling 2 regulates IL-15-primed human NK cell function via control of phosphorylated Pyk2. J Immunol (2010) 185(2):917-28. doi: 10.4049/jimmunol.1000784

113. Lin JX, Li P, Liu D, Jin HT, He J, Ata Ur Rasheed M, et al. Critical Role of STAT5 transcription factor tetramerization for cytokine responses and normal immune function. Immunity (2012) 36(4):586-99. doi: 10.1016/ j.immuni.2012.02.017

114. Delconte RB, Guittard G, Goh W, Hediyeh-Zadeh S, Hennessy RJ, Rautela J, et al. NK Cell Priming From Endogenous Homeostatic Signals Is Modulated by CIS. Front Immunol (2020) 11:75. doi: 10.3389/fimmu.2020.00075

115. Wang XF, Sun R, Hao XL, Lian ZX, Wei HM, Tian ZG. IL-17 constrains natural killer cell activity by restraining IL-15-driven cell maturation via SOCS3. Proc Natl Acad Sci USA (2019) 116(35):17409-18. doi: 10.1073/pnas.1904125116

116. Kim N, Saudemont A, Webb L, Camps M, Ruckle T, Hirsch E, et al. The p110delta catalytic isoform of PI3K is a key player in NK-cell development and cytokine secretion. Blood (2007) 110(9):3202-8. doi: 10.1182/blood2007-02-075366

117. Ruiz-García R, Vargas-Hernández A, Chinn IK, Angelo LS, Cao TN, CobanAkdemir Z, et al. Mutations in PI3K1108 cause impaired natural killer cell function partially rescued by rapamycin treatment. J Allergy Clin Immunol (2018) 142(2):605-17. doi: 10.1016/j.jaci.2017.11.042

118. Tassi I, Cella M, Gilfillan S, Turnbull I, Diacovo TG, Penninger JM, et al. p110 gamma and p110 delta phosphoinositide 3-kinase signaling pathways synergize to control development and functions of murine NK cells. Immunity (2007) 27(2):214-27. doi: 10.1016/j.immuni.2007.07.014

119. Guo HL, Samarakoon A, Vanhaesebroeck B, Malarkannan S. The p110 delta of PI3K plays a critical role in NK cell terminal maturation and cytokine/ chemokine generation. J Exp Med (2008) 205(10):2419-35. doi: 10.1084/ jem.20072327

120. Cantrell DA. Phosphoinositide 3-kinase signalling pathways. J Cell Sci (2001) 114(8):1439-45.

121. Pearce LR, Komander D, Alessi DR. The nuts and bolts of AGC protein kinases. Nat Rev Mol Cell Biol (2010) 11(1):9-22. doi: 10.1038/nrm2822

122. Zoncu R, Efeyan A, Sabatini DM. mTOR: from growth signal integration to cancer, diabetes and ageing. Nat Rev Mol Cell Biol (2011) 12(1):21-35. doi: $10.1038 / \mathrm{nrm} 3025$

123. Marais A, Cherfils-Vicini J, Viant C, Degouve S, Viel S, Fenis A, et al. The metabolic checkpoint kinase mTOR is essential for IL-15 signaling during the development and activation of NK cells. Nat Immunol (2014) 15(8):749+. doi: $10.1038 /$ ni.2936

124. Mao Y, van Hoef V, Zhang X, Wennerberg E, Lorent J, Witt K, et al. IL-15 activates $\mathrm{mTOR}$ and primes stress-activated gene expression leading to prolonged antitumor capacity of NK cells. Blood (2016) 128(11):1475-89. doi: 10.1182/blood-2016-02-698027

125. Wang FJ, Meng M, Mo BH, Yang Y, Ji Y, Huang P, et al. Crosstalks between mTORC1 and mTORC2 variagate cytokine signaling to control NK 
maturation and effector function. Nat Commun (2018) 9(1):4874. doi: 10.1038/s41467-018-07277-9

126. Li D, Wang Y, Yang M, Dong Z. mTORC1 and mTORC2 coordinate early NK cell development by differentially inducing E4BP4 and T-bet. Cell Death Differ (2021). doi: 10.1038/s41418-020-00715-6

127. Yang M, Li D, Chang Z, Yang Z, Tian Z, Dong Z. PDK1 orchestrates early NK cell development through induction of E4BP4 expression and maintenance of IL-15 responsiveness. J Exp Med (2015) 212(2):253-65. doi: $10.1084 /$ jem.20141703

128. Gascoyne DM, Long E, Veiga-Fernandes H, de Boer J, Williams O, Seddon B, et al. The basic leucine zipper transcription factor E4BP4 is essential for natural killer cell development. Nat Immunol (2009) 10(10):1118-U1199. doi: $10.1038 /$ ni.1787

129. Firth MA, Madera S, Beaulieu AM, Gasteiger G, Castillo EF, Schluns KS, et al. Nfil3-independent lineage maintenance and antiviral response of natural killer cells. J Exp Med (2013) 210(13):2981-90. doi: 10.1084/jem.20130417

130. He J, Wang Y, Liu T, Liu G, Chen S, Li Q, et al. Stage-specific requirement of kinase PDK1 for NK cells development and activation. Cell Death Differ (2019) 26(10):1918-28. doi: 10.1038/s41418-018-0263-8

131. Kamizono S, Duncan GS, Seidel MG, Morimoto A, Hamada K, Grosveld G, et al. Nfil3/E4bp4 is required for the development and maturation of NK cells in vivo. J Exp Med (2009) 206(13):2977-86. doi: 10.1084/jem.20092176

132. Yang MX, Chen SS, Du J, He JM, Wang YD, Li ZH, et al. NK cell development requires Tsc1-dependent negative regulation of IL-15triggered mTORC1 activation. Nat Commun (2016) 7:12. doi: 10.1038/ ncomms 12730

133. Brunet A, Bonni A, Zigmond MJ, Lin MZ, Juo P, Hu LS, et al. Akt promotes cell survival by phosphorylating and inhibiting a forkhead transcription factor. Cell (1999) 96(6):857-68. doi: 10.1016/s0092-8674(00)80595-4

134. Guertin DA, Stevens DM, Thoreen CC, Burds AA, Kalaany NY, Moffat J, et al. Ablation in mice of the mTORC components raptor, rictor, or mLST8 reveals that mTORC2 is required for signaling to Akt-FOXO and PKC alpha but not S6K1. Dev Cell (2006) 11(6):859-71. doi: 10.1016/ j.devcel.2006.10.007

135. Cahill CM, Tzivion G, Nasrin N, Ogg S, Dore J, Ruvkun G, et al. Phosphatidylinositol 3-kinase signaling inhibits DAF-16 DNA binding and function via 14-3-3-dependent and 14-3-3-independent pathways. J Biol Chem (2001) 276(16):13402-10. doi: 10.1074/jbc.M010042200

136. Wang S, Xia PY, Huang GL, Zhu PP, Liu J, Ye BQ, et al. FoxO1-mediated autophagy is required for NK cell development and innate immunity. Nat Commun (2016) 7:11023. doi: 10.1038/ncomms11023 doi: ARTN 11023.

137. Deng Y, Kerdiles Y, Chu J, Yuan S, Wang Y, Chen X, et al. Transcription factor Foxol is a negative regulator of natural killer cell maturation and function. Immunity (2015) 42(3):457-70. doi: 10.1016/j.immuni.2015.02.006

138. Samson SI, Richard O, Tavian M, Ranson T, Vosshenrich CA, Colucci F, et al. GATA-3 promotes maturation, IFN-gamma production, and liverspecific homing of NK cells. Immunity (2003) 19(5):701-11. doi: 10.1016/ s1074-7613(03)00294-2

139. Yun S, Lee SH, Yoon SR, Kim MS, Piao ZH, Myung PK, et al. TOX regulates the differentiation of human natural killer cells from hematopoietic stem cells in vitro. Immunol Lett (2011) 136(1):29-36. doi: 10.1016/ j.imlet.2010.11.008

140. Vong QP, Leung W-H, Houston J, Li Y, Rooney B, Holladay M, et al. TOX2 regulates human natural killer cell development by controlling T-BET expression. Blood (2014) 124(26):3905-13. doi: 10.1182/blood-2014-06582965

141. Taveirne S, Wahlen S, Van Loocke W, Kiekens L, Persyn E, Van Ammel E, et al. The transcription factor ETS1 is an important regulator of human NK cell development and terminal differentiation. Blood (2020)136(3):288-98. doi: 10.1182/blood.2020005204

142. Townsend MJ, Weinmann AS, Matsuda JL, Salomon R, Farnham PJ, Biron $\mathrm{CA}$, et al. T-bet regulates the terminal maturation and homeostasis of NK and Valpha14i NKT cells. Immunity (2004) 20(4):477-94. doi: 10.1016/ s1074-7613(04)00076-7

143. Jenne CN, Enders A, Rivera R, Watson SR, Bankovich AJ, Pereira JP, et al. Tbet-dependent S1P5 expression in NK cells promotes egress from lymph nodes and bone marrow. J Exp Med (2009) 206(11):2469-81. doi: 10.1084/ jem.20090525

144. Kallies A, Carotta S, Huntington ND, Bernard NJ, Tarlinton DM, Smyth MJ, et al. A role for Blimp1 in the transcriptional network controlling natural killer cell maturation. Blood (2011) 117(6):1869-79. doi: 10.1182/blood2010-08-303123

145. Loftus RM, Assmann N, Kedia-Mehta N, O’Brien KL, Garcia A, Gillespie C, et al. Amino acid-dependent $\mathrm{cMyc}$ expression is essential for NK cell metabolic and functional responses in mice. Nat Commun (2018) 9 (1):2341. doi: 10.1038/s41467-018-04719-2

146. Leong JW, Schneider SE, Sullivan RP, Parikh BA, Anthony BA, Singh A, et al. PTEN regulates natural killer cell trafficking in vivo. Proc Natl Acad Sci USA (2015) 112(7):E700-9. doi: 10.1073/pnas.1413886112

147. Briercheck EL, Trotta R, Chen L, Hartlage AS, Cole JP, Cole TD, et al. PTEN is a negative regulator of NK cell cytolytic function. J Immunol (Baltimore Md 1950) (2015) 194(4):1832-40. doi: 10.4049/jimmunol.1401224

148. Liu P, Gan W, Chin YR, Ogura K, Guo J, Zhang J, et al. PtdIns(3,4,5)P-3Dependent Activation of the mTORC2 Kinase Complex. Cancer Discovery (2015) 5(11):1194-209. doi: 10.1158/2159-8290.Cd-15-0460

149. Seggewiss R, Einsele H. Immune reconstitution after allogeneic transplantation and expanding options for immunomodulation: an update. Blood (2010) 115(19):3861-8. doi: 10.1182/blood-2009-12234096

150. Dulphy N, Haas P, Busson M, Belhadj S, Peffault de Latour R, Robin M, et al. An unusual CD56(bright) CD16(low) NK cell subset dominates the early posttransplant period following HLA-matched hematopoietic stem cell transplantation. J Immunol (Baltimore Md 1950) (2008) 181(3):2227-37. doi: 10.4049/jimmunol.181.3.2227

151. Cichocki F, Cooley S, Davis Z, DeFor TE, Schlums H, Zhang B, et al. CD56dimCD57+NKG2C+ NK cell expansion is associated with reduced leukemia relapse after reduced intensity HCT. Leukemia (2016) 30(2):45663. doi: 10.1038/leu.2015.260

152. Foley B, Cooley S, Verneris MR, Pitt M, Curtsinger J, Luo X, et al. Cytomegalovirus reactivation after allogeneic transplantation promotes a lasting increase in educated NKG2C+ natural killer cells with potent function. Blood (2012) 119(11):2665-74. doi: 10.1182/blood-2011-10386995

153. Cichocki F, Taras E, Chiuppesi F, Wagner JE, Blazar BR, Brunstein C, et al. Adaptive NK cell reconstitution is associated with better clinical outcomes. JCI Insight (2019) 4(2):e125553. doi: 10.1172/jci.insight.125553

154. Klebanoff CA, Finkelstein SE, Surman DR, Lichtman MK, Gattinoni L, Theoret MR, et al. IL-15 enhances the in vivo antitumor activity of tumorreactive CD8+ T cells. Proc Natl Acad Sci USA (2004) 101(7):1969-74. doi: 10.1073/pnas.0307298101

155. Desbois M, Beal C, Charrier M, Besse B, Meurice G, Cagnard N, et al. IL-15 superagonist RLI has potent immunostimulatory properties on NK cells: implications for antimetastatic treatment. J Immunother Cancer (2020) 8(1): e000632. doi: 10.1136/jitc-2020-000632

156. Waldmann TA. Interleukin-15 in the treatment of cancer. Expert Rev Clin Immunol (2014) 10(12):1689-701. doi: 10.1586/1744666X.2014.973856

157. Conlon KC, Lugli E, Welles HC, Rosenberg SA, Fojo AT, Morris JC, et al. Redistribution, hyperproliferation, activation of natural killer cells and CD8 $\mathrm{T}$ cells, and cytokine production during first-in-human clinical trial of recombinant human interleukin-15 in patients with cancer. J Clin Oncol (2015) 33(1):74-82. doi: 10.1200/JCO.2014.57.3329

Conflict of Interest: The authors declare that the research was conducted in the absence of any commercial or financial relationships that could be construed as a potential conflict of interest.

Copyright $\odot 2021$ Wang and Zhao. This is an open-access article distributed under the terms of the Creative Commons Attribution License (CC BY). The use, distribution or reproduction in other forums is permitted, provided the original author(s) and the copyright owner(s) are credited and that the original publication in this journal is cited, in accordance with accepted academic practice. No use, distribution or reproduction is permitted which does not comply with these terms. 